\title{
FENÔMENOS NÃO-LINEARES NA ELETRO-OXIDAÇÃO DO ÍON
}

\section{BOROIDRETO}

Dissertação apresentada ao Instituto de Química de São Carlos da Universidade de São Paulo como parte dos requisitos para a obtenção do título de mestre em ciências.

Área de Concentração: Físico-Química

Exemplar revisado.

O exemplar original encontra-se disponível no Serviço de Pós-Graduação do IQSC-USP.

ORIENTADOR: PROF. DR. HAMILTON VARELA

\author{
SÃO CARLOS
}

Março, 2012 


\section{AgradeCimentos}

Em primeiro lugar, meus agradecimentos vão para todas as pessoas que me deram suporte durante minha vida. Aos meus pais, sempre presentes e participativos, agradeço pela educação exemplar que me foi dada e pela amizade. Em específico ao meu pai, agradeço pelo companheirismo em diversas atividades extra acadêmicas. À minha irmã agradeço o amor incondicional e aos bons momentos passados ao lado dela. Obrigado também à Scarlet pelo amor, carinho, companheirismo, compreensão, ótimos momentos juntos e por me animar nas diversas vezes em que precisei. Agradeço aos amigos Maikon, Hebert, Gabriela, Kevin, Giovanni, Antônio, Percília, Tiago, Imyra, Waldomiro, Laura, Wagner, Alex, Igor, João Batista e a muitos outros que estiveram sempre ao meu lado.

$\mathrm{Na}$ academia, agradeço a todos os que me ajudaram na execução desse trabalho. Ao professor Hamilton agradeço pela orientação, pelas discussões sempre frutíferas e pela grande paciência que sempre demonstra comigo e com todos os seus alunos. Agradeço aos técnicos e aos funcionários cujas assistências foram essenciais nesses dois anos. Aos companheiros de laboratório, agradeço especialmente a Elton Sitta, por toda a amizade, paciência quase infinita em me ajudar, pelas diversas idas à lanchonete para discutir assuntos quase sempre importantes, pelas divertidas sextas à tarde e por ter me ensinado praticamente tudo o que eu sei sobre eletroquímica. Além dele, agradeço aos companheiros Nickson, Bruno, Marcelo, Adriano, Hyrla, Melke, Emerson, Murilo, Cristiane, Débora, Raphael, Paulo, Graziela e Natália pelas discussões frutíferas e sempre animadas. Obrigado a todos por me ajudar a concluir esse trabalho e, em última instância, ser quem eu sou hoje.

Finalmente agradeço à agência de financiamento CAPES pela bolsa de mestrado fornecida para que o presente trabalho pudesse ser desenvolvido. 


\section{EpíGRAFE}

"You can't always get what you want

But if you try sometimes, yeah,

You just might find you get what you need!"

- Rolling Stones 


\title{
RESUMO
}

MACHADO, E. G. Fenômenos não-lineares na eletro-oxidação do íon boroidreto. 2012. Dissertação - Instituto de Química de São Carlos, Universidade de São Paulo, São Carlos, 2012.

\begin{abstract}
Apesar de toda a atenção dada à eletro-oxidação do íon boroidreto, pela possibilidade de seu uso em células a combustível, pouco se tem discutido a respeito das instabilidades cinéticas associadas a esse processo. A maioria das pesquisas tem como foco o estudo da cinética dos processos na região de baixos sobrepotenciais, numa região relativamente próxima ao estado de equilíbrio termodinâmico. Em uma região afastada do equilíbrio, diferentes mecanismos regem o sistema e desta forma diferentes informações podem ser obtidas. O objetivo da presente dissertação consiste na investigação sistemática da cinética complexa associada aos processos de adsorção, oxidação e interação do íon boroidreto em superfícies policristalinas de platina. As investigações foram realizadas em condições afastadas do equilíbrio utilizandose técnicas eletroquímicas convencionais, incluindo: voltametria cíclica, cronoamperometria, experimentos quase estacionários sob controle potenciostático utilizando diferentes valores de resistência total e transientes de circuito aberto. Dentre os resultados obtidos pode-se destacar: a alta velocidade na redução dos óxidos de platina em transientes de circuito aberto (i.e. 0,5 s), sendo esta mais alta do que para álcoois ou hidrogênio; dois processos auto-catalíticos no perfil de potencial de circuito aberto, que podem ser relacionadas com uma biestabilidade do sistema; as oscilações de corrente obtidas em experimentos quase estacionários utilizando diferentes valores de resistência externa; e as oscilações de baixa frequência obtidas na ausência de resistência externa presentes em uma ampla faixa de potencial. Estes resultados apresentam aspectos tecnológicos, como a relação direta entre o baixo tempo de redução de óxido e a perda de desempenho de células a combustível por conta de difusão de combustível, e fundamentais, como a emergência de oscilações e a caracterização do sistema como NNDR, que podem contribuir para um maior entendimento sobre o uso deste combustível. Esses são resultados ainda não explorados na literatura e o presente trabalho propõe o preenchimento desta lacuna.
\end{abstract}

Palavras Chaves: Boroidreto, Sistemas Complexos, Oscilação, Eletro-oxidação, Potencial de circuito aberto. 


\begin{abstract}
MACHADO, E. G. Non-linear phenomena during borohydride electro-oxidation. 2012. Dissertation - Instituto de Química de São Carlos, Universidade de São Paulo, São Carlos, 2012.

Despite all attention given to the electro-oxidation of the ion borohydride, for its applicability in fuel cells, few discussions have been made on the kinetical instabilities possibly present on this process. Most researches focuses on the kinetical study of these processes at a low overpotential range, relatively close to the thermodynamic equilibrium. Under far from thermodynamic condition, different mechanisms rule the system and different information can be obtained. The present dissertation aims at a systematic investigation of the complex kinetic associated to the adsorption, oxidation and interaction processes of the borohydride ion over polycrystalline platinum surface. The investigations were realized under far from thermodynamic equilibrium conditions using conventional electrochemical techniques, including: cyclic voltammetry, chronoamperometry, quasi-steady experiments under potentiostac control using different values of external resistance and open circuit transients. Among the results it is possible to highlight: the fast reduction of platinum oxides in open circuit transients (i.e. $0.5 \mathrm{~s}$ ), which is faster than when alcohol or hydrogen is used; two autocatalytic processes in the open-circuit profile, which can be related to a bistability of the system; current oscillations in quasi-steady experiments using different values of external resistances; and the low frequency oscillations obtained without external resistance under a large potential range. These results show technological aspects, such as the direct relationship of the short time for oxide reduction and the performance loss of a fuel cell by crossover, and fundamental, such as the emergency of oscillations and the characterization of the system as a N-NDR, which can contribute to a better understanding of this fuel. These are yet not explored results in literature and the present research propose filling the gap.
\end{abstract}

Keywords: Borohydride, Complex Systems, Oscillations, Electro-oxidation, Open circuit potential. 


\section{SUMÁRIO}

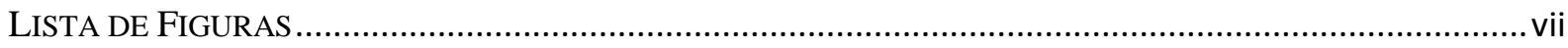

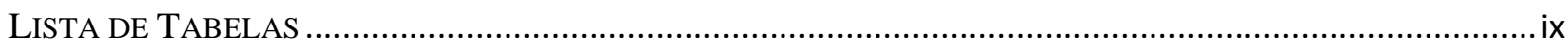

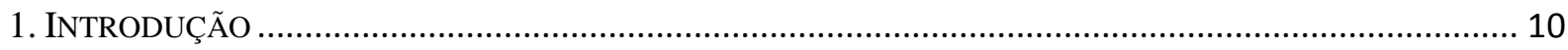

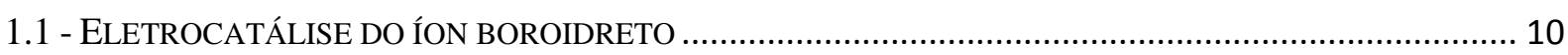

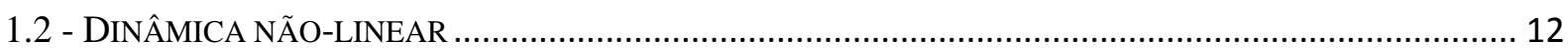

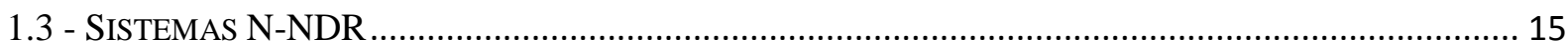

1.4 - INTERAÇÃO EM POTENCIAL DE CIRCUITO ABERTO ……........................................................ 18

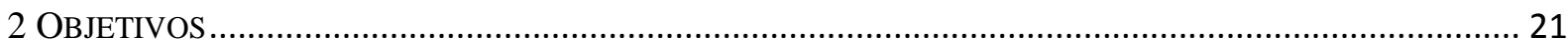

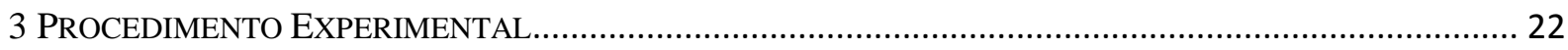

3.1 - ELETRODOS

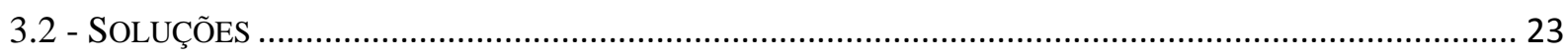

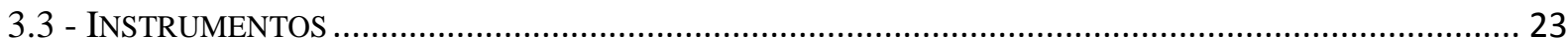

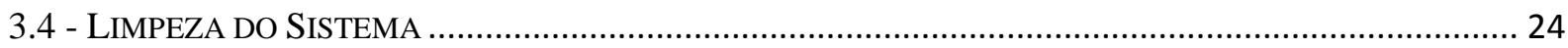

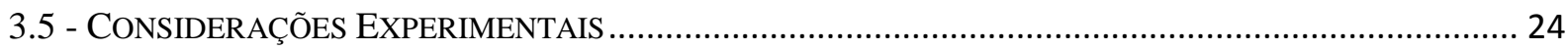

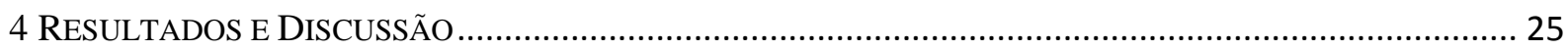

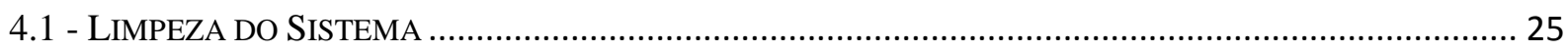

4.2 - INTERAÇÃO EM Potencial DE CiRCUITO ABERTO (PCA) .......................................................... 28

4.3 - OSCILAÇÕES NA PRESENÇA DE RESISTÊNCIA EXTERNA.............................................................. 35

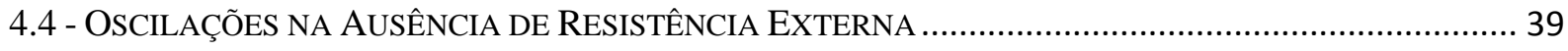

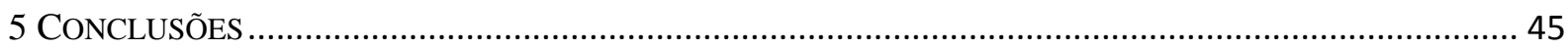

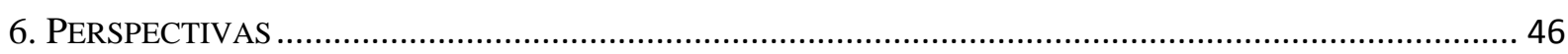

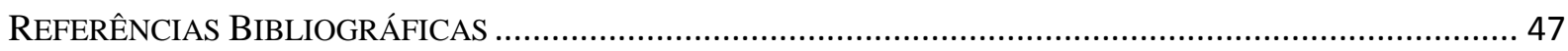




\section{LiSTA DE Figuras}

Figura 1 - Identificação das bifurcações do tipo sela-nó. Em (a), curva em forma de $\mathrm{N}$ da corrente versus o potencial do eletrodo. Em (b), curva da corrente em função da voltagem aplicada. Em (c) um digrama da resistência ôhmica em função da voltagem aplicada, ilustrando a região de biestabilidade. Figura retirada referência [15].

Figura 2 - Ciclos de retro-alimentação positivos e negativos necessários para a obtenção de oscilações. $\Phi$ representa o potencial do eletrodo, Y representa alguma espécie inibidora como por exemplo o óxido do metal e I representa a corrente. Figura retirada da referência [15]

Figura 3 - Curva $I / \varphi_{D L}$ em formato de $N$ para um oscilador N-NDR. As oscilações ocorrem para um valor fixo de $\mathrm{U}$ (condições potenciostáticas) ao redor do ramo com a NDR como indicado pelas linhas. Note que, ao contrário de U, $\varphi$ não é constante durante as oscilações. (b) Localização qualitativa de regiões de biestabilidade e oscilações no plano de parâmetros $U / R_{\Omega}$ para osciladores N-NDR. (c) Curva para I/ $\varphi$ estacionários de osciladores HN-NDR (linha cheia) e curva $\mathrm{I} / \varphi$ em formato de $\mathrm{N}$ para o rápido subsistema (veja no texto). As oscilações ocorrem para um valor fixo de $\mathrm{U}$ (condições potenciostáticas) e corrente fixa (condições galvanostáticas) ao redor de um ramo com inclinação positiva como indicado pelas linhas para o caso de corrente constante. (d) Localização qualitativa de regiões oscilatórias e biestáveis no plano de parâmetros $\mathrm{U} / \mathrm{R}_{\Omega}$ para osciladores HN-NDR. Note que a região oscilatória persiste até o limite em que $\mathrm{R}_{\Omega}$ tende ao infinito (caso galvanostático). Figura retirada da referência [15]. 16

Figura 4 - Transientes de potencial de circuito aberto durante a interação entre uma superfície de platina oxidada $\left(t_{\mathrm{p}}\right.$ em 1,4 V vs RHE por $1.000 \mathrm{~s}$ ) e metanol 0,5 $\mathrm{M}$ em $\mathrm{HClO}_{4} 0,1 \mathrm{M}$ (linha cheia), $\mathrm{H}_{2} \mathrm{SO}_{4}$ 0,5 M (linha tracejada) e $\mathrm{H}_{2} \mathrm{SO}_{4}+10^{-4} \mathrm{M} \mathrm{Cl}^{-} 0,5 \mathrm{M}$ (linha pontilhada). Os íons cloreto foram injetados juntos com o metanol em $t=0$. Figura retirada da referência [31].

Figura 5 - Voltametria cíclica do eletrodo de platina em hidróxido de sódio 1 M. Velocidade de varredura $=100 \mathrm{mV} \cdot \mathrm{s}^{-1}$ 25

Figura 6 - Perfil voltamétrico obtido após procedimento evitando que a camisa do eletrodo fosse molhada

Figura 7 - Voltamograma cíclico típico para a eletro-oxidação de boroidreto em placa de platina, com $v=0,1 \mathrm{~V} \cdot \mathrm{s}^{-1}$ 27 
Figura 8 - Perfis de PCA para uma superfície de platina oxidada em 1,5 V vs RHE por $150 \mathrm{~s}$ (equivalente a uma cobertura de 1,2 monocamadas). (a) polarização sem o boroidreto e adição deste pouco antes do início da medida; onde $t=0$ significa a adição (b) polarização com $o$ boroidreto. $\omega=1000 \mathrm{rpm}$.

Figura 9 - Transientes de potencial de circuito aberto durante a interação entre boroidreto e platina, oxidada em $1,5 \mathrm{~V}$ em diferentes tempos. $\omega=1000 \mathrm{rpm}$. 30

Figura 10 - Interação em potencial de circuito aberto entre o íon boroidreto e a superfície de platina oxidada em diferentes velocidades de rotação. 34

Figura 11 - Oscilações de corrente durante a eletro-oxidação de boroidreto $5 \mathrm{mM}$ em platina. Eletrólito: $\mathrm{NaOH} 1 \mathrm{M}$, Resistência Externa: $500 \Omega$, Velocidade de varredura: $10 \mathrm{mV} \cdot \mathrm{s}^{-1}, \mathrm{~T}=$ $25 \pm 1{ }^{0} \mathrm{C}$. 36

Figura 12 - Regiões de oscilação potenciodinâmica em um mapa do tipo resistência externa vs potencial aplicado. 37

Figura 13 - Cronoamperometria em $1.4 \mathrm{~V}$ vs RHE com uma resistência externa ligada em serie ao eletrodo de trabalho de $0,5 \mathrm{k} \Omega$. O pré-tratamento utilizado foi de $1,5 \mathrm{~V}$ vs RHE por $1 \mathrm{~s}$. 38

Figura 14 - Varredura no sentido de aumento de potencial, do íon boroidreto $5 \mathrm{mM}$, a $1 \mathrm{mV} . \mathrm{s}^{-1}$. Prétratamento de $1,5 \mathrm{~V}$ vs RHE por $15 \mathrm{~s}$ 40

Figura 15 - Varredura no sentido de diminuição de potencial, do íon boroidreto $5 \mathrm{mM}$, a $1 \mathrm{mV} . \mathrm{s}^{-1}$. Pré-tratamento de $1,5 \mathrm{~V}$ vs RHE por $15 \mathrm{~s}$.

Figura 16 - Cronoamperometrias em diferentes potenciais por 500 s. Pré-tratamento de 1,5 V vs RHE por $15 \mathrm{~s}$ antes de cada medida. 


\section{LiSTA DE TABELAS}

Tabela 1 - Relação entre o pH e o tempo de meia vida do íon boroidreto. Tabela retirada da referência [40]. 31

Tabela 2 - Características das oscilações obtidas em duas diferentes condições: varredura de potencial com resistência externa acoplada e varredura de potencial sem resistência externa acoplada...... 41 


\section{INTRODUÇÃO}

\section{1 - ELETROCATÁLISE DO ÍON BOROIDRETO}

Nos últimos 20 anos tem sido discutido largamente o uso de células combustíveis alimentadas diretamente com combustíveis líquidos, por conta de sua facilidade de armazenamento e alta densidade de energia [1-4]. Em especial, como combustível, o boroidreto tem se destacado há algum tempo. Isso porque ele tem uma capacidade teórica de liberação de oito elétrons por molécula em sua oxidação, em potenciais baixos $\left(E^{0}=-1,24 \mathrm{~V}\right.$ vs NHE) [5] remetendo à, previamente citada, alta densidade de energia. Além disso, a célula a combustível direta de boroidreto (CCDB) apresenta as vantagens de uma célula combustível alcalina: a maior parte das reações ocorre mais rapidamente em meio alcalino do que em meio ácido e nesse meio é possível utilizar outros eletrocatalisadores além da platina, sem perda de desempenho ou estabilidade. O boroidreto também apresenta algumas vantagens, sendo elas: ele é atóxico, facilmente armazenável e relativamente estável em soluções alcalinas [6]. Essas características são essenciais e altamente desejáveis em um combustível. A reação de oxidação em uma célula alimentada por esse combustível pode ser representada por:

$$
\mathrm{BH}_{4}^{-}+8 \mathrm{OH}^{-} \rightarrow \mathrm{BO}_{2}^{-}+6 \mathrm{H}_{2} \mathrm{O}+8 e^{-} \quad \mathrm{E}^{0}=-1,24 \mathrm{~V}_{\mathrm{NHE}}
$$

Já a reação no cátodo pode ser descrita como:

$$
2 \mathrm{O}_{2}+4 \mathrm{H}_{2} \mathrm{O}+8 e^{-} \rightarrow 8 O \mathrm{H}^{-} \quad \mathrm{E}^{0}=0,401 \mathrm{~V}_{\mathrm{NHE}}
$$

O que resulta como reação global para esta célula:

$$
\mathrm{BH}_{4}^{-}+2 \mathrm{O}_{2} \rightarrow \mathrm{BO}_{2}^{-}+2 \mathrm{H}_{2} \mathrm{O} \quad \mathrm{E}_{\text {célula }}=1,64 \mathrm{~V}
$$

O processo anódico depende de fatores como o material do catalisador, da composição da solução e da temperatura, entre outros [7-9]. Dependendo do material do eletrodo, rotas paralelas de reação podem ocorrer. Para materiais que não são cataliticamente ativos para a reação de hidrólise, esta acontece em menor escala. Este é o caso do eletrodo de ouro, que foi proposto como uma alternativa ao tradicional eletrodo de platina, considerando que o primeiro 
eletrodo catalisa a hidrólise do boroidreto menos do que o segundo [5]. Esta é uma hidrólise heterogênea que ocorre em competição com a reação de oxidação de oito elétrons do boroidreto e acontece em várias etapas, sendo algumas descritas da seguinte forma:

$$
\begin{aligned}
& \mathrm{BH}_{4}^{-}+\mathrm{H}_{2} \mathrm{O} \rightarrow \mathrm{BH}_{3} \mathrm{OH}^{-}+\mathrm{H}_{2} \\
& \mathrm{BH}_{3} \mathrm{OH}^{-}+\mathrm{H}_{2} \mathrm{O} \rightarrow \mathrm{BO}_{2}^{-}+3 \mathrm{H}_{2}
\end{aligned}
$$

Essa reação de hidrólise não é desejável para uma célula a combustível, pois resulta em uma perda de eficiência. Algumas soluções são propostas para resolver este impasse. No trabalho de Martins e colaboradores [10] é proposto o uso da tioureia (TU) em uma proporção em concentração TU/BH ${ }_{4}{ }^{-}$de 0,6 . Essa adição inibe a hidrólise do boroidreto e a liberação de hidrogênio, permitindo a oxidação direta do $\mathrm{BH}_{4}{ }^{-}$em um processo de oito elétrons (meio alcalino $3 \mathrm{M} \mathrm{NaOH}$ ), sobre platina.

Segundo Tarozaitè e colaboradores [11] seria ainda possível eliminar a hidrólise do íon boroidreto pela modificação do eletrodo de platina. De acordo com este estudo, o uso de um eletrodo de carbono vítreo modificado em soluções de complexo de platina com estanho e ácido clorídrico geraria um eletrodo capaz de oxidar o boroidreto sem a hidrólise deste.

Elder e Hickling [12] sugeriram que das duas reações mais significativas para os íons boroidreto - a sua oxidação e sua hidrólise - maior ênfase foi tradicionalmente devotada à segunda. Esta situação vem mudando consideravelmente, uma vez que muitos trabalhos têm sido desenvolvidos abordando os dois temas. Entretanto, as duas reações foram estudadas separadamente e seus efeitos foram qualitativamente classificados como desejáveis ou não.

Prova da mudança supra referida encontra-se no trabalho de Concha e colaboradores [13]. Neste trabalho de 2011 é feita uma discussão a respeito do mecanismo de oxidação do boroidreto, avaliada por meio de técnicas de FTIR in situ. O trabalho contribui com a discussão a respeito da formação de produtos da hidrólise heterogênea do boroidreto. Neste trabalho foi constatado que em eletrodos de ouro a extensão da BOR (do inglês borohydride oxidative reaction) é bastante dependente do potencial. Em baixos potenciais, a hidrólise heterogênea é possível, mas limitada. Em potenciais intermediários, o ouro catalisa mais rapidamente os produtos de hidrólise e em seguida catalisa uma oxidação eletroquímica parcial das espécies $\mathrm{BH}_{3} \mathrm{OH}_{\text {ads }}^{-}$. Por fim, em potenciais altos, a BOR fica predominante e a reação procede até o final: a formação de $\mathrm{BO}_{2}^{-}$. 
Além da complexidade inerente ao processo global de transferência de oito elétrons, instabilidades cinéticas na forma de dinâmica biestável e oscilatórias podem assumir um papel determinante na reação, sob algumas condições.

\section{2 - DINÂMICA NÃO-LINEAR}

Segundo Varela [14], a física Newtoniana descreve um mundo linear, onde quando se conhecem dois estados do sistema, pode-se saber como o sistema evoluirá. Essa física é baseada em evoluções lineares e é restrita às regiões próximas à condição de equilíbrio termodinâmico. A partir do reconhecimento dos sistemas caóticos uma nova abordagem foi apresentada: sistemas descritos por equações diferenciais ordinárias, não-lineares e acopladas, com grande dependência das condições iniciais. O caos só pode ser atingido longe do estado de equilíbrio termodinâmico e sob essas condições outras manifestações podem ser observadas como cinética excitatória, multiestável e oscilatória.

Segundo Krischer e Varela [15] os sistemas eletroquímicos operam usualmente em condições afastadas do equilíbrio termodinâmico, portanto ajustando-se parâmetros é possível obter regiões de biestabilidade. A biestabilidade de estados estacionários pode ser considerada, segundo Krischer [16], como o fenômeno não-linear mais simples. Este se faz presente mesmo em sistemas de uma só variável. Pode ser citado como exemplo sistemas $\mathrm{N}$ NDR, nos quais a variável é o potencial da dupla camada $\varphi_{\mathrm{DL}}$. Adicionalmente, esse fenômeno pode ser definido como a coexistência de diferentes estados com os mesmos valores de parâmetros externos, na mesma região de parâmetros.

Uma das formas mais comuns de instabilidade cinética está associada à presença de uma região de resistência diferencial negativa (NDR, negative differential resistance). Na grande maioria dos casos, a NDR aparece numa curva estacionária de corrente versus potencial na forma de N. Segundo Krischer e Varela [15] essa variação negativa acontece por três motivos:

1. Se acontecer a adsorção dependente do potencial de uma espécie e esta diminuir a área disponível do eletrodo com o aumento da polarização inibindo assim completamente a reação. Essa adsorção deve ainda aumentar caso o sobrepotencial para a reação aumente.

2. Se a taxa da constante heterogênea diminuir com o aumento da polarização, o que pode acontecer segundo duas origens distintas: ou por adsorbatos que não inibam completamente a 
reação, mas aumentam a energia de ativação desta ou por desorção do catalisador sendo que esta dependa do potencial.

3. Se os cátions forem oxidados ou os ânions forem reduzidos e a concentração das espécies eletroativas cair com o aumento do potencial. Isso pode ocorrer em baixas forças iônicas devido aos efeitos eletrostáticos, segundo Frumkin [17].

A Figura 1 apresenta uma representação esquemática de como uma NDR surge numa curva em formato de $\mathrm{N}$, assim como sua conexão com a biestabilidade.
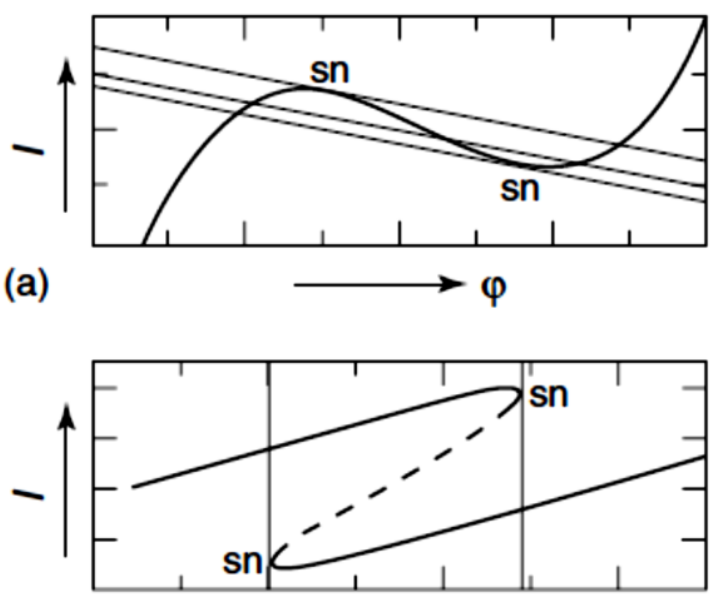

(b)
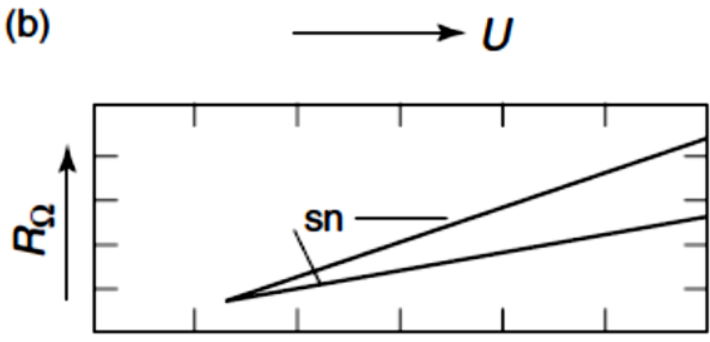

(c)

\section{$U$}

Figura 1 - Identificação das bifurcações do tipo sela-nó. Em (a), curva em forma de $\mathrm{N}$ da corrente versus o potencial do eletrodo. Em (b), curva da corrente em função da voltagem aplicada. Em (c) um digrama da resistência ôhmica em função da voltagem aplicada, ilustrando a região de biestabilidade. Figura retirada referência [15].

Na Figura 1 é possível observar que a região de biestabilidade encontra-se confinada entre os pontos que indicam bifurcações do tipo sela-nó (saddle node, sn) que caracterizam o formato de N à curva. Dentro dessa região é possível se destacar a NDR que é caracterizada como sendo uma variação negativa da corrente com o aumento do potencial do eletrodo. A NDR indica a região de biestabilidade que fornece um ciclo de retro-alimentação positiva ao sistema. Entretanto, para se obter as oscilações é necessário que exista um ciclo negativo que retorne o sistema ao estado inicial. Um exemplo desse ciclo pode ser encontrado na Figura 2. 


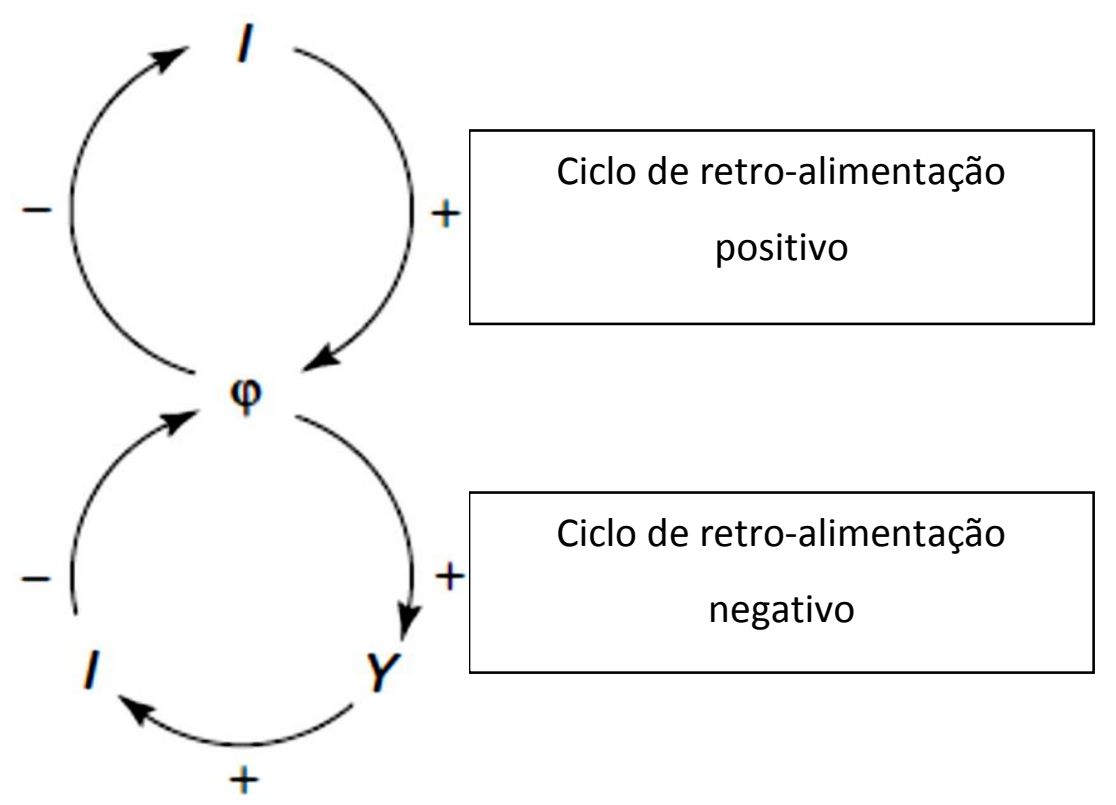

Figura 2 - Ciclos de retro-alimentação positivos e negativos necessários para a obtenção de oscilações. $\varphi$ representa o potencial do eletrodo, Y representa alguma espécie inibidora como, por exemplo, o óxido do metal e I representa a corrente. Figura retirada da referência [15].

Supondo-se inicialmente que haja uma flutuação positiva no potencial do eletrodo. Caso isso ocorra, como se trata de uma região de resistência diferencial negativa, a corrente deve diminuir. A diminuição da corrente causará, portanto, um aumento do potencial do eletrodo. Dessa forma, esse é um ciclo de retro-alimentação positivo. Paralelamente, com a variação positiva do potencial do eletrodo, ocorrerá um aumento de produção da espécie Y (por exemplo o óxido do metal). Com a formação dessa espécie aumentada, mais elétrons devem fluir para a interface e a corrente deve aumentar. $\mathrm{O}$ aumento da corrente ocasiona uma diminuição do potencial do eletrodo caracterizando-se o ciclo de retro-alimentação negativo. Com esses dois ciclos acoplados, temos as condições necessárias para que o sistema apresente oscilações.

Em geral, sistemas eletrocatalíticos apresentam ciclos positivo e negativo associados às isotermas de adsorção dependentes do potencial de diferentes espécies. Por exemplo, no caso mais estudado, a eletro-oxidação de moléculas orgânicas pequenas sobre platina, oscilações resultam da intersecção entre isotermas de adsorção de monóxido de carbono e espécies oxigenadas.

A cinética interfacial de todos os sistemas eletroquímicos que exibem fenômenos nãolineares possuem uma propriedade em comum, uma resistência diferencial negativa (NDR) na característica curva corrente-potencial. O tipo mais frequente de NDR, a assim chamada N- 
NDR, é associada com um formato de $\mathrm{N}$ na curva corrente-potencial. $\mathrm{O}$ outro tipo de sistema NDR possui um formato de $\mathrm{S}$ em sua curva $\mathrm{I} / \varphi_{\mathrm{DL}}$ e por essa razão é assim chamado de sistema S-NDR. Com o objetivo de se esclarecer um tema abordado na Seção 4.3, será agora explicado em detalhes as características de um sistema do tipo N-NDR.

\section{3 - SISTEMAS N-NDR}

A maioria das instabilidades cinéticas presentes em sistemas eletroquímicos estão associadas com uma dependência com formato de $\mathrm{N}$ entre a corrente e o potencial do eletrodo. Este formato é bastante comum e se apresenta com facilidade, motivo este pelo qual as oscilações são tão frequentemente encontradas em sistemas eletroquímicos. Os motivos pelos quais uma região com esse formato é formada encontra-se exposto na Seção 1.2. Uma característica interessante desse tipo de sistema é o fato de que o potencial do eletrodo atua como uma variável auto-catalítica.

Segundo Krischer [16], sempre que existe pelo menos um processo lento adicional que introduz um ciclo negativo de retro-alimentação em um sistema que já possui uma N-NDR existe uma região de parâmetros nas quais o sistema exibe oscilações estáveis. Dependendo das características desse ciclo negativo, podem-se distinguir dois tipos de osciladores, que são chamados de N-NDR e HN-NDR. Uma característica que os diferencia é que os sistemas HNNDR oscilam sob controles de potencial e de corrente, enquanto que os sistemas N-NDR nunca oscilam sob controle de corrente. Os sistemas do tipo HN-NDR são assim chamados por conta da expressão em inglês hidden $N$-NDR, que significa N-NDR escondido. Esse nome é assim dado por conta do comportamento apresentado pela Figura 3. 

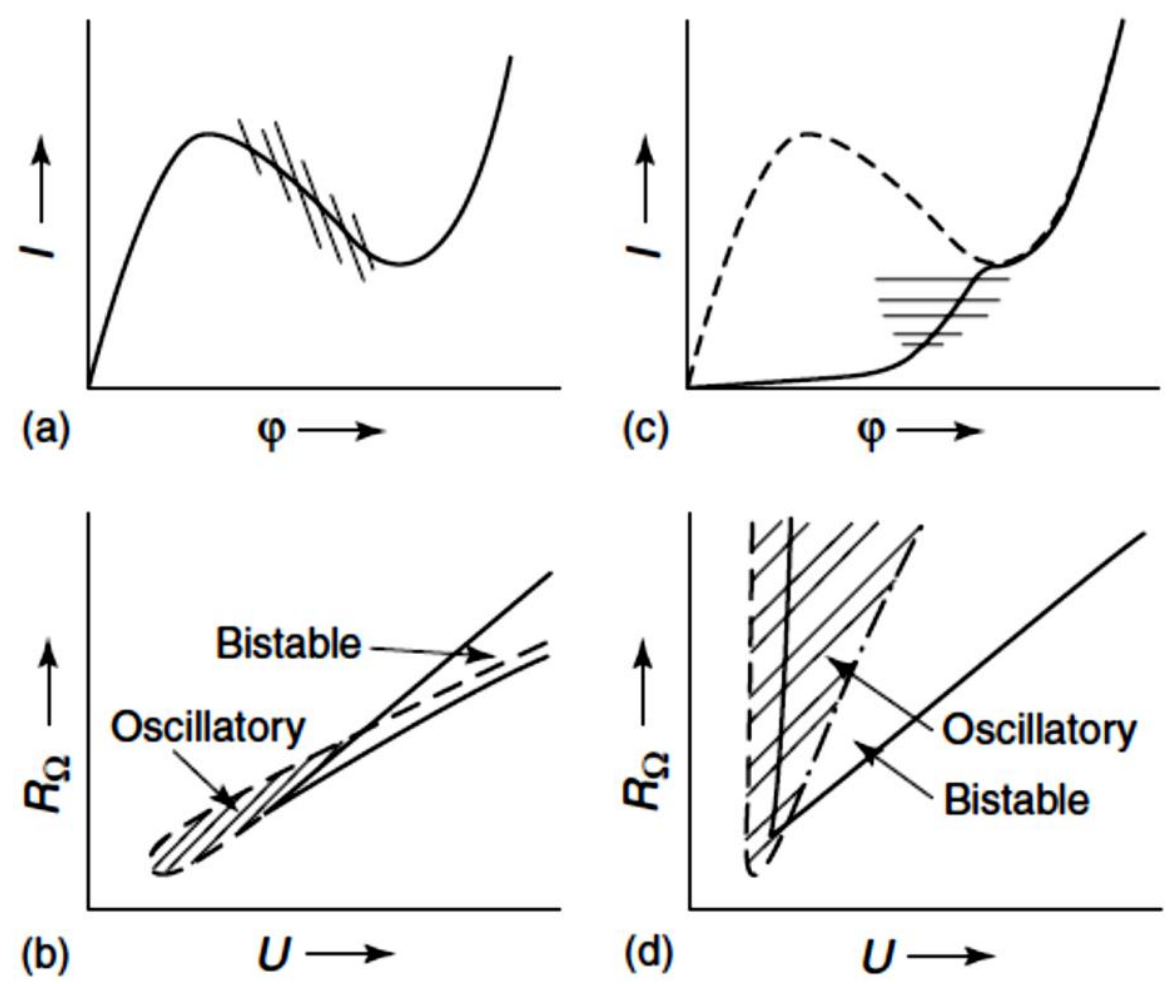

Figura 3 - Curva $I / \varphi_{\mathrm{DL}}$ em formato de $\mathrm{N}$ para um oscilador N-NDR. As oscilações ocorrem para um valor fixo de $\mathrm{U}$ (condições potenciostáticas) ao redor do ramo com a NDR como indicado pelas linhas. Note que, ao contrário de U, $\varphi$ não é constante durante as oscilações. (b) Localização qualitativa de regiões de biestabilidade e oscilações no plano de parâmetros $U / R_{\Omega}$ para osciladores N-NDR. (c) Curva para $\mathrm{I} / \varphi$ estacionários de osciladores $\mathrm{HN}$ NDR (linha cheia) e curva $\mathrm{I} / \varphi$ em formato de $\mathrm{N}$ para o rápido subsistema (veja no texto). As oscilações ocorrem para um valor fixo de $U$ (condições potenciostáticas) e corrente fixa (condições galvanostáticas) ao redor de um ramo com inclinação positiva como indicado pelas linhas para o caso de corrente constante. (d) Localização qualitativa de regiões oscilatórias e biestáveis no plano de parâmetros $\mathrm{U} / \mathrm{R}_{\Omega}$ para osciladores $\mathrm{HN}-\mathrm{NDR}$. Note que a região oscilatória persiste até o limite em que $\mathrm{R}_{\Omega}$ tende ao infinito (caso galvanostático). Figura retirada da referência [15].

O rápido subsistema apresentado na legenda da Figura 3 refere-se ao fato de que segundo Krischer e colaboradores [15] formalmente qualquer sistema HN-NDR pode ser considerado como composto por um subsistema. Este contém uma curva de polarização estacionária em formato de $\mathrm{N}$ na qual a NDR está escondida por pelo menos um passo adicional, lento e dependente do potencial, da cinética interfacial do sistema. Desta forma, chama-se HN-NDR por apresentar uma curva NDR escondida.

O tipo mais simples de manifestação de oscilação provém do modelo de ativadorinibidor. Neste modelo, supõe-se que o ciclo de retro-alimentação negativo é mais lento do que o ciclo de retro-alimentação positivo. Matematicamente, segundo Krischer e colaboradores [15] esse tipo de oscilador pode ser descrito de acordo com as seguintes equações acopladas: 


$$
\begin{gathered}
C \frac{d \varphi}{d t}=-i_{F}(\varphi Y)+\frac{U-\varphi}{R_{\Omega}} \\
\frac{d Y}{d t}=g(\varphi, Y)
\end{gathered}
$$

Em que g é determinado pela cinética de $\mathrm{Y}$ e depende do sistema a ser investigado. A corrente faradaica depende agora de dois termos, $\varphi$ e Y.

Em estados estacionários as equações $\mathrm{d} \varphi / \mathrm{dt}=0$ e $\mathrm{dY} / \mathrm{dt}=0$ são resolvidas simultaneamente. Algumas condições gerais podem ser apresentadas apesar das condições restritas para a estabilidade do estado estacionário.

a) Se as condições $Z_{F}^{-1}<0$ e $R_{\Omega}>\left|Z_{F}\right|$ são atendidas, o estado estacionário é um ponto de sela sendo portanto instável. Sob muitas condições experimentais (mas não todas) o sistema é então biestável. As oscilações nunca se manifestarão ao redor de um ponto de sela.

b) O sistema pode possuir soluções oscilatórias se:

b1) $Z_{F}(\omega=0)<0$ e $R_{\text {crit }}<R_{\Omega}<Z_{F}(\omega=0)$

ou

b2) $Z_{F}(\omega=0)>0$ para algum $\omega \neq 0: \operatorname{Re}\left(Z_{F}\right)<0$

$\operatorname{Im}\left(Z_{F}\right)=0$ e $R_{\text {crit }}<R_{\Omega}$

onde $\omega$ significa que a impedância faradaica é uma quantidade dependente da frequência, $Z_{F}(\omega=0)$ é a impedância faradaica de frequência zero e $\mathrm{R}_{c r i t}$ é a resistência mínima necessária para que se possam emergir as oscilações. De modo geral, as oscilações existem para resistências ôhmicas mais baixas do que as necessárias para se observar a biestabilidade. Adicionalmente é possível concluir que os sistemas N-NDR não oscilam em modo galvanostático, uma vez que essa é uma condição limite para o caso potenciostático com uma resistência externa tendendo ao infinito.

O presente trabalho se faz necessário uma vez que uma abordagem tão rica em detalhes e informações não foi utilizada para se estudar um sistema que tem sido amplamente discutido na literatura. Adicionalmente, o entendimento das instabilidades cinéticas em sistemas eletrocatalíticos pode resultar na obtenção de importantes informações mecanísticas, algumas vezes não disponíveis em condições próximas ao estado de equilíbrio 
termodinâmico. O tipo mais simples de instabilidade cinética a ser estudada é a biestabilidade que, como apresentado na Seção 4.2, encontra-se presente na interação do íon boroidreto com a superfície de platina oxidada por conta dos processos de auto-catálise.

\section{4 - Interação em Potencial de Circuito Aberto}

Apesar das vantagens apresentadas para o uso de boroidreto como combustível de células a combustível direto (CCD), a eletro-oxidação deste íon apresenta algumas desvantagens. Pode-se apontar, por exemplo, a cinética lenta da reação anódica, a possível migração (do inglês crossover) de combustível ao compartimento do cátodo e a dificuldade em se retirar os subprodutos da reação de oxidação do boroidreto [18-21]. A migração de $\mathrm{BH}_{4}{ }^{-}$do ânodo ao cátodo através da membrana resulta em uma perda de combustível e uma utilização não eficiente do oxidante, afetando negativamente o desempenho da célula a combustível. Ao se adicionar a solução de boroidreto no compartimento do combustível, uma quantidade deste migra pela membrana e faz com que o potencial de circuito aberto dos cátodos decresça abruptamente. Esse comportamento é indesejável em uma célula a combustível, uma vez que o potencial do cátodo deve permanecer o mais alto possível. Adicionalmente, essa migração tem uma grande influência na reação de redução de oxigênio (RRO) no cátodo [22]. Com boroidreto de sódio em solução de hidróxido de sódio [23], eletrocatalisadores como Pt, Au e Ag se tornam menos efetivos para a RRO do que quando estão em solução pura de hidróxido de sódio e o potencial de circuito aberto cai tremendamente.

Experimentos sobre a interação em circuito aberto (CA) entre um combustível e a superfície oxidada de um catalisador em experimentos de meia célula podem fornecer informações importantes sobre o efeito da migração de combustíveis em sistemas práticos. A interação entre hidrogênio e diversas outras moléculas orgânicas pequenas com a superfície de platina oxidada foram estudadas [24-32]. Na Figura 4 encontra-se exposta a interação entre o combustível metanol e a superfície de platina oxidada. 


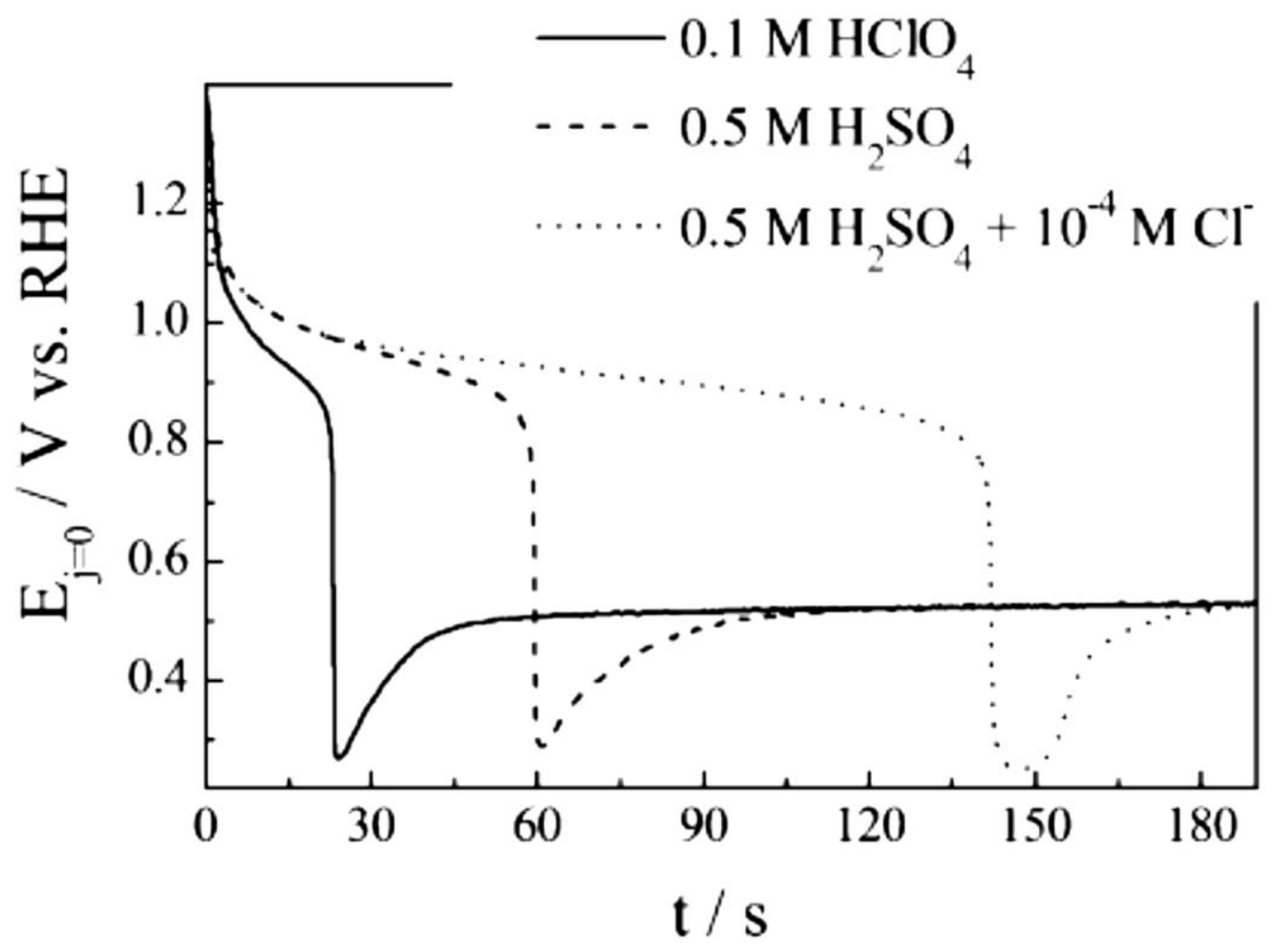

Figura 4 - Transientes de potencial de circuito aberto durante a interação entre uma superfície de platina oxidada ( $t_{\mathrm{p}}$ em $1,4 \mathrm{~V}$ vs RHE por $\left.1.000 \mathrm{~s}\right)$ e metanol $0,5 \mathrm{M}$ em $\mathrm{HClO}_{4} 0,1 \mathrm{M}$ (linha cheia), $\mathrm{H}_{2} \mathrm{SO}_{4} 0,5 \mathrm{M}$ (linha tracejada) e $\mathrm{H}_{2} \mathrm{SO}_{4}+10^{-4} \mathrm{M}$ $\mathrm{Cl}^{-} 0,5 \mathrm{M}$ (linha pontilhada). Os íons cloreto foram injetados juntos com o metanol em $t=0$. Figura retirada da referência [31].

O entendimento atual sobre os mecanismos de redução em CA dos óxidos de platina compreendem uma etapa inicial de lenta redução em altas coberturas de óxido seguida por uma produção auto-catalítica de sítios de platina livres, como pode ser observado na Figura 4 $[33,34]$.

Podlovchenko e colaboradores $[28,27 ; 30 ; 32 ; 35]$ realizaram uma serie de trabalhos a respeito dos fatores que influenciavam os perfis de interação em potencial de circuito aberto. Eles trabalharam com diversas espécies como metanol, ácido fórmico, formaldeído e $\mathrm{CO}$ e exploraram o esquema de reações conjugadas para extrair parâmetros cinéticos associados com a interação entre essas moléculas e a superfície de platina oxidada. Baseado nesses trabalhos, Varela e colaboradores $[24 ; 31 ; 34]$ recentemente estudaram aspectos que trouxeram mais compreensão ao assunto como, por exemplo, o efeito de troca de posição (do inglês place exchange). Essa observação foi feita baseando-se no fato de que a concentração de óxido na superfície seria aproximadamente invariável para pequenas quedas na quantidade total de óxido. Além disso, outro tópico a ser adicionado à compreensão do assunto se refere à 
produção auto-catalítica de sítios de platina livre. Esse processo será explicado em detalhes na Seção 4.2.

Resultados experimentais da eletro-oxidação de íons boroidreto apresentam indícios da presença de instabilidades cinéticas $[5-7 ; 10]$. Estes resultados justificam os estudos realizados neste trabalho sobre a interação em potencial de circuito aberto que, como demonstrado na Seção 4.2, apresentam características inéditas. Desta forma, um novo conjunto de informações a respeito desse sistema foi apresentado acrescentando à discussão na literatura. 


\section{OBJETIVOS}

O objetivo do presente projeto consiste na investigação sistemática da cinética complexa associada aos processos de adsorção e oxidação do íon boroidreto sobre superfície policristalina de platina. A reação foi estudada em condições afastadas do estado de equilíbrio termodinâmico e em dois distintos regimes: um em potencial de circuito aberto a fim de se observar a biestabilidade presente nos processos auto-catalíticos e outro com resistência externa acoplada em altos valores de sobrepotencial para se observar a emergência de oscilações de corrente. 


\section{Procedimento Experimental}

\section{1 - ELETRODOS}

De acordo com o experimento a ser realizado foram utilizados diferentes configurações da platina policristalina. Para os experimentos de interação em potencial de circuito aberto, foi utilizada uma esfera de platina de área geométrica $0,16 \mathrm{~cm}^{2}$ adaptada a um acessório da Autolab $^{\circledR}$ para eletrodos rotatórios. A rugosidade desse eletrodo era aproximadamente unitária, checada antes de cada experimento por meio do cálculo de sua área eletroativa. Utilizando-se um voltamograma estável da platina calculou-se a área eletroativa do eletrodo integrando-se a região de dessorção de hidrogênio. Esse cálculo foi feito considerando-se que a oxidação de uma monocamada de hidrogênio nessa região produz $210 \mu \mathrm{C} . \mathrm{cm}^{-2}$ [36]. A área eletroativa calculada foi utilizada para se normalizar a corrente, sendo então chamada de densidade de corrente (j). Para os demais experimentos, utilizou-se uma placa de platina de área geométrica $0,26 \mathrm{~cm}^{2}$ com rugosidade aproximadamente um, e área eletroativa aferida de forma semelhante àquela usada para a esfera de platina. Como contra-eletrodo foi utilizada uma rede de Pt platinizada, pois dessa forma sua área superficial aumenta significantemente. Todos os potenciais foram medidos com relação ao eletrodo reversível de hidrogênio, preparado na mesma solução do eletrólito de suporte. O motivo de se usar o eletrodo de referência reversível de hidrogênio (RHE, do inglês Reversible Hydrogen Electrode) em meio alcalino ao invés do tradicional $\mathrm{Hg} / \mathrm{HgO}$ baseia-se em um equilíbrio de vantagens e desvantagens. O primeiro é mais fácil de limpar, manusear e preparar se comparado com o segundo. Entretanto, neste tipo de meio, ao invés do típico valor de $\mathrm{E}_{\mathrm{A}}=0 \mathrm{~V}$, utiliza-se um valor de $\mathrm{E}_{\mathrm{B}}=-0.826 \mathrm{~V}$ (valor para $1 \mathrm{M}$ de $\mathrm{OH}^{-}$). $\mathrm{O}$ deslocamento do potencial apresentado pelo eletrodo pode ser calculado de acordo com a seguinte equação [37]:

$$
E^{H E}=E^{0, S H E}+2,303 \frac{R T}{F} \log \left(a_{H^{+}}\right)
$$

Nessas condições, considerando-se que $\log \left(\mathrm{a}_{\mathrm{H}}\right)$ é igual a $-\mathrm{pH}$, que $\mathrm{T}=25{ }^{0} \mathrm{C}$ temos um deslocamento de $-0,059 \mathrm{~V}$ no eletrodo para cada aumento de unidade de $\mathrm{pH}$. No caso apresentado, considerando-se $1 \mathrm{M}$ de $\mathrm{NaOH}$, tem-se $\mathrm{pH}=14$ e portanto um deslocamento de - 
0,826 V. Como o eletrodo é preparado com a mesma solução do eletrólito, a formação de hidrogênio sobre platina versus essa referência se dará em $0 \mathrm{~V}$.

\section{2 - SOLUÇÕES}

Em todos os experimentos realizados utilizaram-se os seguintes materiais:

- Água ultra pura (18,2 M $\Omega \cdot \mathrm{cm}^{-1}$ Millipore $\left.^{\circledR}\right)$

- Boroidreto de Sódio $\left(\mathrm{NaBH}_{4}\right.$, Sigma-Aldrich, 95\%)

- Hidróxido de sódio (Sigma-Aldrich, 99.99\%)

- Nitrogênio $\left(99,996 \%\right.$ White Martins $\left.{ }^{\circledR}\right)$

Todas as medidas foram realizadas em meio alcalino, com $5 \mathrm{mM}$ do ânion boroidreto em meio $1 \mathrm{M}$ de hidróxido de sódio. Esses valores foram adotados utilizando-se como referência o trabalho de Finkelstein et al.[5] considerando-se este um dos mais atuais sobre o assunto. $\mathrm{O}$ meio alcalino foi escolhido porque nele o boroidreto apresenta maior estabilidade. De acordo com de Leon et al.[1], uma célula a combustível utilizando boroidreto só pode ser operada em meio fortemente alcalino porque o ânion é rapidamente hidrolisado em meios aquosos ácidos e a uma velocidade considerável em meios aquosos neutros [38].

$$
\mathrm{BH}_{4}^{-}+2 \mathrm{H}_{2} \mathrm{O} \rightarrow \mathrm{BO}_{2}^{-}+4 \mathrm{H}_{2}
$$

\section{3 - INSTRUMENTOS}

Todas as medidas eletroquímicas foram realizadas em um potenciostato Autolab ${ }^{\circledR}$ (modelo PGSTAT302N) equipado com um módulo Scan-Gen (gerador de varredura analógico). A rotação do eletrodo foi realizada utilizando-se um módulo de eletrodo disco rotatório da Autolab ${ }^{\circledR}$. Para o caso da adição externa de resistências, utilizou-se uma plataforma de resistências variáveis Minipa ${ }^{\circledR}$ modelo MDR610. Utilizou-se, para todas as aferições de massa, uma balança analítica da marca Sartorius ${ }^{\circledR}$ BP210S, com precisão de 0,1 mg. Para pequenos volumes, utilizou-se uma micropipeta da marca Eppendorf ${ }^{\circledR}$ de volumes entre 100 e $1000 \mu \mathrm{L}$. 


\section{4 - LIMPEZA DO SISTEMA}

Antes de qualquer medida, para garantir que não havia impurezas presentes no sistema, uma limpeza rigorosa foi feita em todos os aparatos utilizados. O procedimento baseou-se em uma imersão de toda a vidraria utilizada em ácido sulfonítrico por 12 horas. Em seguida, toda a vidraria era lavada e submersa em água Mili-Q, a fim de se realizar um procedimento de ebulição da água, que era repetido por 3 vezes. Os eletrodos de trabalho e contra-eletrodo eram imersos em ácido sulfonítrico, que era aquecido até próximo da ebulição. Em seguida, esses eletrodos eram lavados exaustivamente em água quente. Por fim, o eletrodo de trabalho era aquecido ao rubro por 1 minuto, a fim de se garantir uma rugosidade próxima a 1 . Finalmente a célula eletroquímica era montada, e um gás de arraste (tipicamente nitrogênio) era purgado a fim de se expulsar o oxigênio presente na atmosfera da célula (e continuava sendo purgado durante os experimentos). Além da limpeza química, também se utilizou a limpeza eletroquímica por meio de 100 voltametrias cíclicas com alta velocidade de varredura, tipicamente de $2 \mathrm{~V} . \mathrm{s}^{-1}$.

\section{5 - CONSIDERAÇõeS EXPERIMENTAIS}

A área eletroativa do eletrodo de trabalho foi calculada antes de cada experimento e as correntes medidas normalizadas por esta e chamadas de densidade de corrente. $\mathrm{O}$ cálculo da área foi realizado integrando-se a região de dessorção do hidrogênio. Com o resultado da integração, sabendo-se a velocidade de varredura utilizada e considerando que a oxidação de uma monocamada de hidrogênio nessa região produz $210 \mu \mathrm{C} . \mathrm{cm}^{-2}$ [36], pode-se calcular a área eletroativa do eletrodo de trabalho.

Para o caso das medidas de potencial de circuito aberto, a formação da camada de óxido de platina se deu por polarização em $1.5 \mathrm{~V}$ vs RHE por diferentes tempos, dependendo do experimento. 


\section{Resultados e Discussão}

\section{1 - LIMPEZA DO SISTEMA}

Antes de cada medida eletroquímica realizada durante a execução deste trabalho, uma voltametria cíclica a $100 \mathrm{mV} . \mathrm{s}^{-1}$ foi realizada a fim de atestar se o sistema encontrava-se em boas condições de limpeza e, caso sim, calcular a área eletroativa do eletrodo. Inicialmente, um problema de contaminação surgiu no sistema e encontra-se representado na Figura 5.

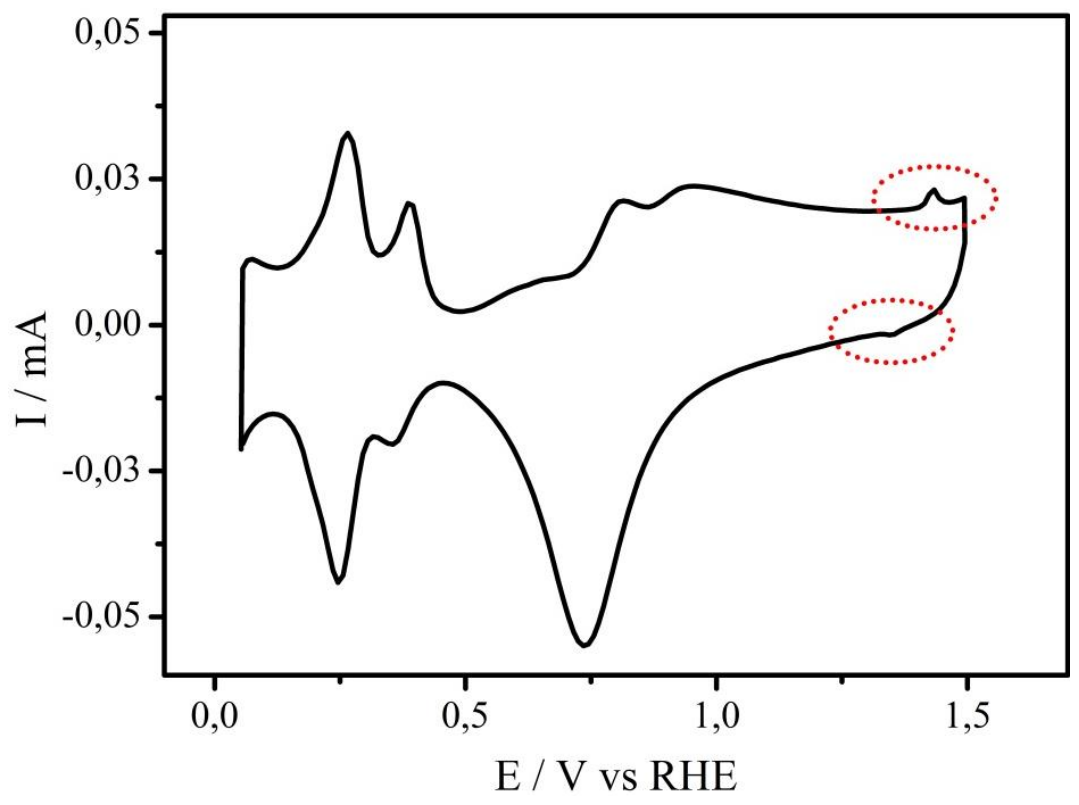

Figura 5 - Voltametria cíclica do eletrodo de platina em hidróxido de sódio $1 \mathrm{M}$. Velocidade de varredura $=100 \mathrm{mV} . \mathrm{s}^{-1}$.

Como se pode observar em aproximadamente $1,4 \mathrm{~V}$ vs RHE, encontra-se um pico de oxidação e um corresponde pico de redução praticamente reversíveis. Esse pico indicava a existência de algum composto estranho ao sistema e não se encontrava relatado na literatura. Objetivando-se sanar este problema, diversas medidas foram adotadas. A primeira foi a troca do procedimento de limpeza para o que foi exposto nesse trabalho (anteriormente utilizava-se permanganato de potássio e peróxido de hidrogênio para limpeza). A mudança surtiu efeito $a$ priori, entretanto com o passar do tempo, o pico voltou a aparecer no voltamograma. Em seguida, foram substituídas todas as partes de vidro da célula, por meio da confecção de um sistema novo. Além disso, o hidróxido de sódio utilizado foi testado por outros colegas e não apresentou problemas. Outra medida tomada foi a substituição do eletrodo de trabalho. Foram testados alguns deles e uns apresentavam o problema, outros não. Finalmente, após mais de 1 
ano tentando lidar com o problema, foi descoberto que nos dois eletrodos que apresentaram problemas era a contaminação com óxido da solda/fio de contato. O eletrodo de trabalho em forma de placa era soldado em um fio de contato, encamisados em uma camisa de vidro. Esta, entretanto, estava sofrendo infiltrações e provavelmente a causa da contaminação era algum óxido formado na solda do fio. O problema foi sanado ao evitar que a camisa do eletrodo fosse molhada nas posteriores medidas. O procedimento aparentemente resolveu o problema e o perfil voltamétrico obtido pode ser visto na Figura 6.

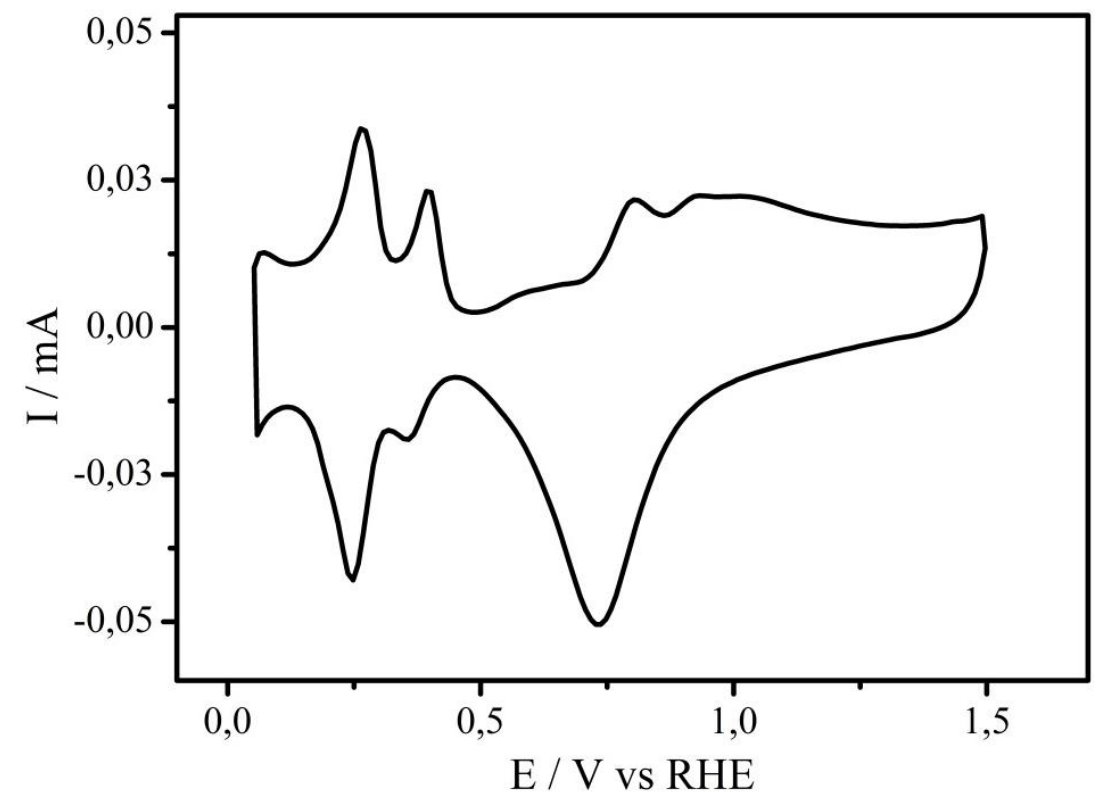

Figura 6 - Perfil voltamétrico obtido após procedimento evitando que a camisa do eletrodo fosse molhada.

É possível notar que o pico em 1,4 V vs RHE não encontra-se mais presente e a partir dessa qualificação do perfil é que os estudos subsequentes puderam ser realizados. Segundo Hamann e colaboradores [37] , entre $0,45 \mathrm{~V}$ e $0,55 \mathrm{~V}$ encontra-se uma corrente que flui para carregar a dupla camada elétrica $\left(j_{\mathrm{c}}\right)$. Se a capacitância dessa camada é $C_{\mathrm{d}}$, então $j_{\mathrm{c}}=C_{\mathrm{d}}$. $\mathrm{dE} / \mathrm{d} t$ : para $C_{\mathrm{d}}=100 \mu \mathrm{F} . \mathrm{cm}^{-2}$ e $v=\mathrm{dE} / \mathrm{d} t=100 \mathrm{mV} \cdot \mathrm{s}^{-1}, j_{\mathrm{c}}=10 \mu \mathrm{A} \cdot \mathrm{cm}^{-2}$.

Acima de $0,55 \mathrm{~V}$, a quimisorção de óxido começa, com o processo:

$$
\mathrm{Pt}+\mathrm{OH}^{-} \rightarrow \mathrm{Pt}-\mathrm{OH}+e^{-}
$$

e acima de $0,8 \mathrm{~V}$,

$$
\mathrm{Pt}-\mathrm{OH}+\mathrm{OH}^{-} \rightarrow \mathrm{Pt}-\mathrm{O}+\mathrm{H}_{2} \mathrm{O}+e^{-}
$$


Acima de 1,6V começa o desprendimento de oxigênio e em potenciais mais altos uma fase de óxido pode ser formada na superfície da platina (i.e. uma com uma espessura maior do que de uma monocamada). Conforme o potencial é invertido, qualquer molécula de oxigênio presente nas vizinhanças do eletrodo é reduzida juntamente com a camada de óxido quimisorvida. Em baixos potenciais existe uma pequena região de dupla camada seguida por uma deposição de hidreto como

$$
\mathrm{Pt}+\mathrm{H}_{2} \mathrm{O}+e^{-} \rightarrow \mathrm{Pt}-\mathrm{H}+\mathrm{OH}^{-}
$$

Finalmente, próximo do potencial termodinâmico para o par $\mathrm{H}_{2} / \mathrm{H}_{2} \mathrm{O}$, existe uma forte evolução de hidrogênio que pode ser re-oxidada uma vez que a direção do potencial é invertida novamente.

Uma vez que o perfil da voltametria da platina em meio alcalino se encontrava semelhante ao da literatura [37], foram realizadas voltametrias de platina com o íon boroidreto presente na solução do eletrólito Dessa forma, um perfil típico de voltametria da eletro-oxidação de boroidreto em platina encontra-se ilustrado na Figura 7.

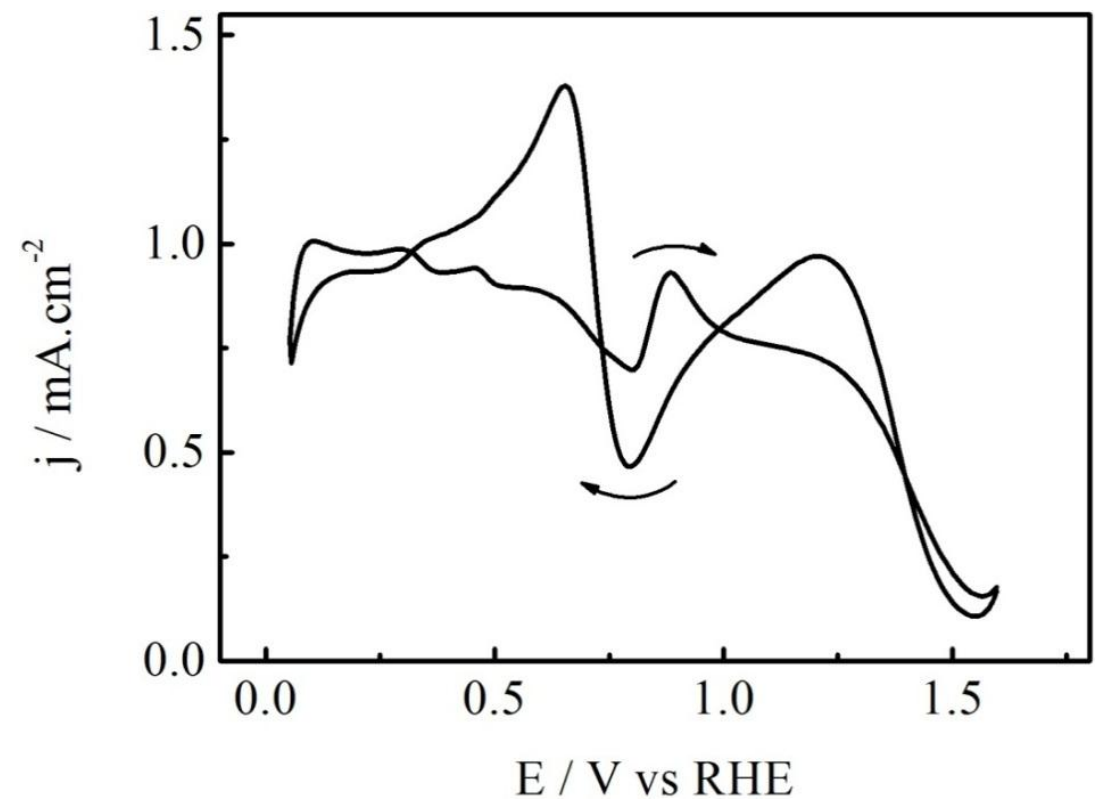

Figura 7 - Voltamograma cíclico típico para a eletro-oxidação de boroidreto em placa de platina, $\operatorname{com} v=0,1 \mathrm{~V} . \mathrm{s}^{-1}$.

Os principais aspectos vão de encontro aos publicados anteriormente [5]. Focando na varredura negativa de potencial, duas regiões ativas com máximos centrados em 1,2 e 0,6 V são discerníveis. Ambos os processos de reativação associados com esses máximos são 
causados pela regeneração de sítios não bloqueados de platina. $\mathrm{O}$ primeiro processo encontrado em potenciais mais positivos é causado pela redução de óxidos de platina, similar ao encontrado durante a eletro-oxidação de hidrogênio [39] e muitas outras moléculas orgânicas em platina $[24 ; 33]$. O mecanismo relacionado aos processos de envenenamento superficial, que ocorrem quando o potencial diminui e a subsequente reativação em aproximadamente $0,60 \mathrm{~V}$, não é conhecido.

\section{2 - Interação em Potencial de Circuito Aberto (PCA)}

Como início aos estudos sobre as instabilidades dinâmicas, foram realizados os estudos sobre a dinâmica biestável do sistema. Para se avaliar tal propriedade foi estudada a interação em potencial de circuito aberto entre o íon boroidreto e a superfície de platina oxidada. A Figura 8 apresenta o resultado da interação para duas diferentes condições: (a) $\mathrm{BH}_{4}^{-}$adicionado em t=0 s, e (b) $\mathrm{BH}_{4}^{-}$adicionado logo após a etapa de crescimento de óxido. O transiente de circuito aberto registrado na ausência de boroidreto também é apresentado em (c). O tempo $\tau$ que o sistema leva para alcançar o PCA na presença de $B H_{4}^{-}$ (aproximadamente 0,2 V) é muito similar nos dois casos, indicando que a quantidade de óxido formada é aproximadamente não afetada pela presença do $\mathrm{BH}_{4}^{-}$. Por conveniência, todos os experimentos seguintes tiveram a etapa de formação de óxido acontecendo na presença do íon boroidreto. 


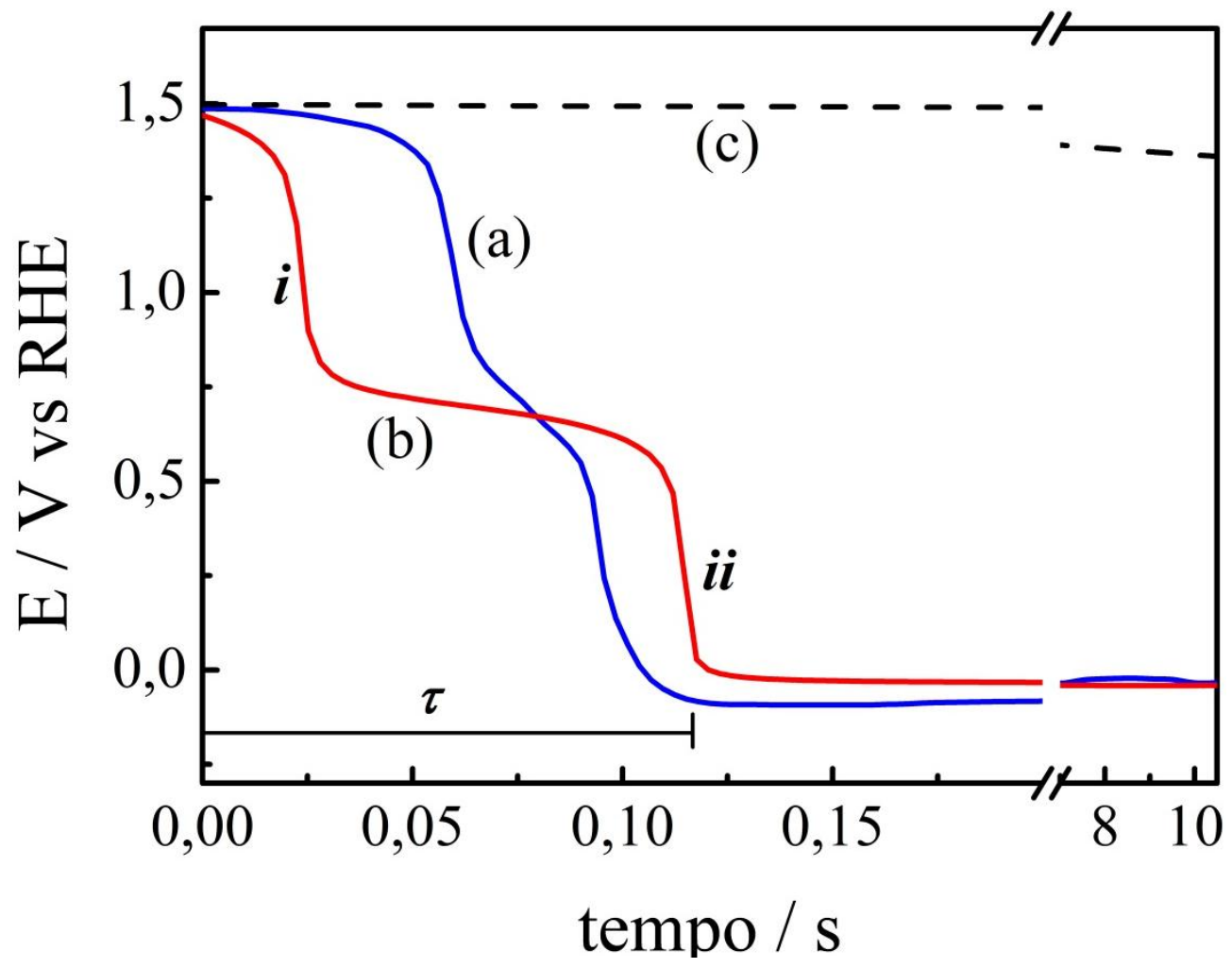

Figura 8 - Perfis de PCA para uma superfície de platina oxidada em 1,5 V vs RHE por $150 \mathrm{~s}$ (equivalente a uma cobertura de 1,2 monocamadas). (a) polarização sem o boroidreto e adição deste pouco antes do início da medida; onde $\mathrm{t}=0$ significa a adição (b) polarização com o boroidreto. $\omega=1000 \mathrm{rpm}$.

O principal aspecto a ser destacado é o baixo tempo de transiente $\tau$ apresentado na Figura 8 (a) e (b) necessário para o consumo de PtO, como representado pela queda de potencial. O valor de aproximadamente $0,15 \mathrm{~s}$ é cerca de duas a três ordens de magnitude menor do que o observado para a interação de outros combustíveis com quantidade comparáveis de óxido $[5 ; 24 ; 27 ; 28 ; 30-34]$. Por exemplo, tempos de cerca de 50 s e de 5 minutos foram apresentados para os casos de metanol [24] e hidrogênio [28]. Mesmo considerando as diferenças experimentais e outras especificidades, a diferença de tempo é grande o suficiente para dizer que o boroidreto pode reduzir o filme de óxido em um incrivelmente baixo tempo.

Um segundo aspecto a ser explorado no experimento descrito na Figura 8 (a) e (b), se refere à queda de potencial em duas etapas, no transiente de circuito aberto. Como visto na Figura 8 (b), após certo tempo em altos valores, o potencial cai abruptamente para cerca de $0,75 \mathrm{~V}$ (região $i$ ) e, depois de um platô de mudança lenta, uma outra queda abrupta se procede em aproximadamente $0,5 \mathrm{~V}$ (região $i$ ). Finalmente, o potencial alcança seu valor de equilíbrio em aproximadamente 0,02 V. Apesar de ainda discernível, a queda em duas etapas na Figura 8 (a) é menos pronunciada e pode ser atribuída às condições de transporte mal definidas 
quando o boroidreto é adicionado. Esse transiente em duas etapas parece ser um aspecto único da redução de óxidos de platina por boroidreto em potenciais de circuito aberto. Não se pode descartar, entretanto, que a primeira queda lenta encontrada em potenciais muito altos não ocorre para os casos de interação com moléculas orgânicas pequenas (ver como exemplo a Fig. 4 em [33]) e também para $\mathrm{H}_{2}$ dissolvido. $\mathrm{O}$ ponto a ser destacado aqui é que essa queda ocorre em velocidade comparável àquela para a segunda queda de potencial em baixos valores.

A Figura 9 mostra o efeito do tempo de polarização, ou a quantidade de óxido de platina [33], no transiente de circuito aberto. Os perfis dos transientes são preservados e um aumento inesperado em $\tau$ acompanha o aumento da quantidade de óxido.

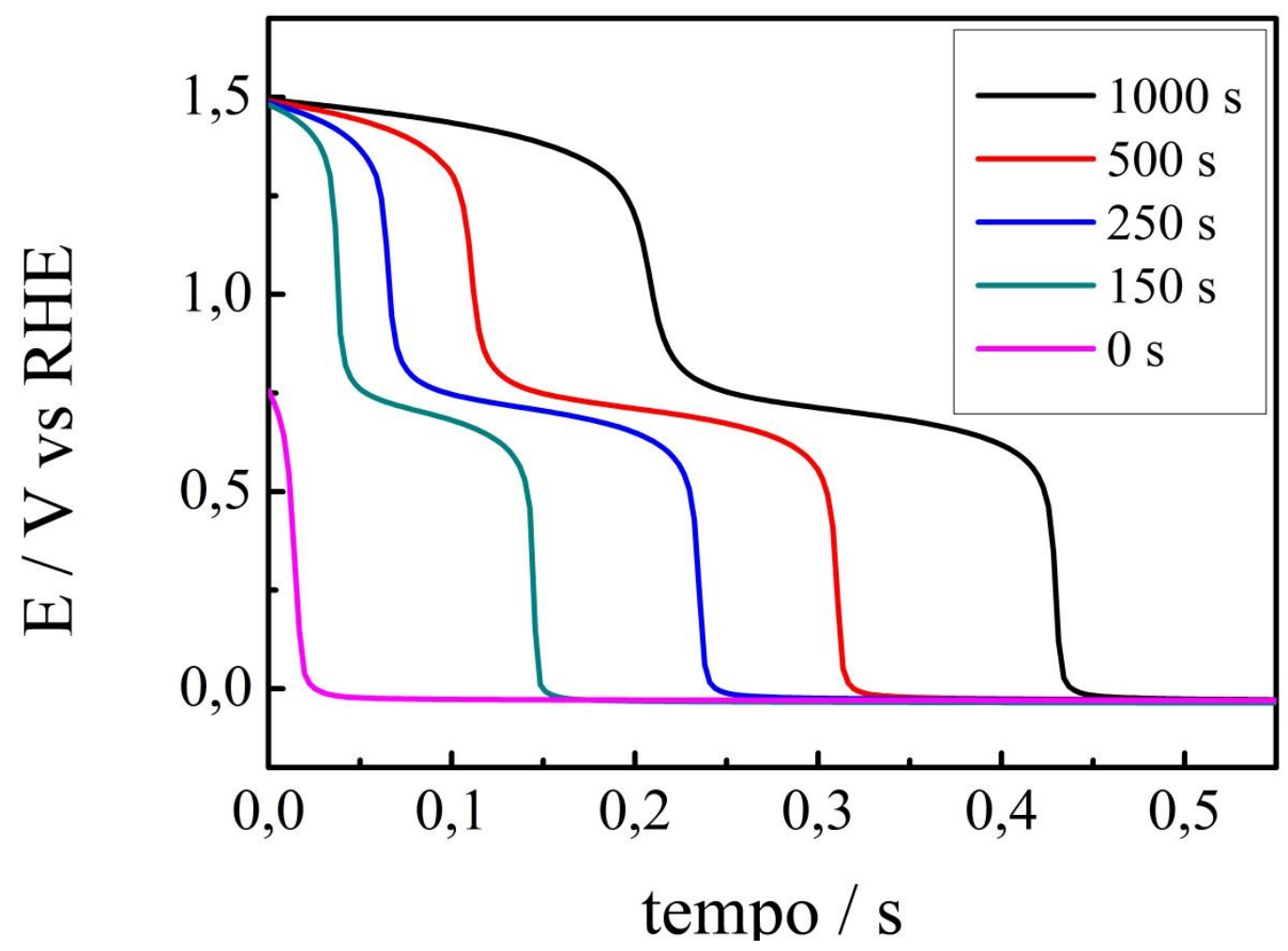

Figura 9 - Transientes de potencial de circuito aberto durante a interação entre boroidreto e platina, oxidada em $1,5 \mathrm{~V}$ em diferentes tempos. $\omega=1000 \mathrm{rpm}$.

$\mathrm{Na}$ tentativa de interpretar os resultados obtidos em termos do mecanismo, Concha et. al. [13] relataram recentemente um estudo espectroscópico sobre a eletro-oxidação de boroidreto em platina. Os autores sugerem a ocorrência de três processos simultâneos: hidrólises homogênea, heterogênea e a eletro-oxidação. A hidrólise homogênea pode ser descartada por conta do alto pH utilizado aqui. Segundo Don Gervasio [40], a seguinte tabela a respeito da estabilidade do íon boroidreto em meio aquoso pode ser apresentada: 
Tabela 1 - Relação entre o pH e o tempo de meia vida do íon boroidreto. Tabela retirada da referência [40].

\begin{tabular}{|c|c|}
\hline pH & Tempo de meia vida do $\mathbf{B H}_{\mathbf{4}}^{-}$ \\
\hline 4,0 & 0,0037 segundos \\
\hline 5,0 & 0,037 segundos \\
\hline 5,5 & 0,12 segundos \\
\hline 6,0 & 0,37 segundos \\
\hline 7,0 & 3,7 segundos \\
\hline 8,0 & 36,8 segundos \\
\hline 9,0 & 6,1 minutos \\
\hline 10,0 & 61,4 minutos \\
\hline 11,0 & 10,2 horas \\
\hline 12,0 & 4,3 dias \\
\hline 13,0 & 42,6 dias \\
\hline 14,0 & 426,2 dias \\
\hline
\end{tabular}

Esta tabela foi confeccionada baseada na equação apresentada no trabalho de Richardson e colaboradores [41]. Neste trabalho, apresenta-se a seguinte equação para o cálculo da estabilidade do íon boroidreto em meio aquoso:

$$
\log _{10} t_{\frac{1}{2}}(\min )=\mathrm{pH}-(0,034 \mathrm{~T}-1,92)
$$

onde $\mathrm{t}_{1 / 2}$ é o tempo de meia vida em minutos e $\mathrm{T}$ a temperatura (em Kelvin).

Considerando que o eletrólito utilizado neste trabalho foi uma solução $1 \mathrm{M}$ de $\mathrm{NaOH}$ e que o $\mathrm{pH}$ era próximo de 14,0, pode-se considerar que o tempo de meia vida do íon boroidreto era de aproximadamente 426 dias. Desta forma, descarta-se a hidrólise homogênea como significativa ao trabalho. Entretanto, devem ocorrer em paralelo tanto a hidrólise heterogênea quanto a eletro-oxidação. Nós racionalizamos a queda explosiva do potencial durante os transientes de circuito aberto em termos de uma produção auto-catalítica de sítios de platina livres [39].

Uma produção auto-catalítica de sítios de platina livre pode ser definida como um processo que envolve duas espécies, tipicamente um sítio de platina livre e outro ocupado 
com alguma espécie adsorvida, que leva à liberação dessa espécie e a consequente formação de dois sítios de platina. $\mathrm{O}$ esquema a seguir apresenta uma representação desse fenômeno:

$$
A+B \rightarrow 2 A
$$

Dessa forma, pode-se dizer que houve uma produção auto-catalítica de sítios de platina, uma vez que um sítio livre levou a formação de dois. A auto-catálise encontra-se também presente na interação de álcoois com a superfície de platina oxidada. Em 2008, Batista e colaboradores [24] publicaram um trabalho na qual essa interação foi avaliada através da espectroscopia de infravermelho in situ. Os autores propuseram um esquema geral para a interação de metanol e etanol com a superfície de platina oxidada:

$$
R-\mathrm{CH}_{2}-\mathrm{OH}+x P t-\mathrm{O}+y \mathrm{Pt} \rightarrow\left(\mathrm{H}_{3} \mathrm{CH}\right) \mathrm{mCOn}+(1+x-n) \mathrm{H}_{2} \mathrm{O}+(x+y) P t
$$

onde para metanol: $\mathrm{R}=\mathrm{H}, \mathrm{x}=3, \mathrm{y}=3, \mathrm{~m}=0$ e $\mathrm{n}=2$ e para etanol: $\mathrm{R}=\mathrm{CH}_{3}, \mathrm{x}=\mathrm{y}=1, \mathrm{e} \mathrm{m}=\mathrm{n}=1$.

É possível observa na equação (r8) o fenômeno de auto-catálise. Como reagentes temos xPt-O e yPt. Esses dois reagentes fornecem como produto $(\mathrm{x}+\mathrm{y}) \mathrm{Pt}$, ou seja, y sítios de platina livre e x sítios de platina com óxido formam, no final da reação, $(\mathrm{x}+\mathrm{y})$ sítios de platina livre. A esse efeito damos o nome de auto-catálise, pois a formação de sítios livres de platina induz a formação de outros sítios, até que todos estejam livres.

As duas transições abruptas de potencial de circuito aberto observadas na Figura 9 guardam semelhança com uma etapa auto-catalítica descoberta anteriormente para outros agentes redutores. Baseado no entendimento atual da eletro-oxidação de boroidreto em platina é possível sugerir uma etapa de formação auto-catalítica durante a interação em circuito aberto entre o boroidreto e PtO. Assume-se que as etapas seguintes acontecem durante a eletro-oxidação parcial a $\mathrm{BH}_{2} \mathrm{OH}$ :

$$
\begin{gathered}
P t+\mathrm{BH}_{4}^{-}+\mathrm{OH}^{-} \rightarrow \mathrm{Pt}-\mathrm{BH}_{3}+\mathrm{H}_{2} \mathrm{O}+2 e^{-} \\
P t-\mathrm{BH}_{3}+\mathrm{OH}^{-} \rightarrow \mathrm{Pt}-\mathrm{BH}_{3} \mathrm{OH}^{-} \\
\mathrm{Pt}-\mathrm{BH}_{3} \mathrm{OH}^{-}+\mathrm{OH}^{-} \rightarrow \mathrm{Pt}+\mathrm{BH}_{2} \mathrm{OH}+\mathrm{H}_{2} \mathrm{O}+2 e^{-}
\end{gathered}
$$

Como nenhuma corrente líquida flui em condições de circuito aberto, para que as etapas (r9)-(r11) aconteçam, elas devem estar acopladas com a reação de oxidação: 


$$
2 \mathrm{Pt}-\mathrm{O}+4 e^{-}+2 \mathrm{H}_{2} \mathrm{O} \rightarrow 2 \mathrm{Pt}+4 \mathrm{OH}^{-}
$$

Portanto, a equação global para as reações conjugadas [30] (r9) a (r12) será,

$$
\mathrm{Pt}+2 \mathrm{Pt}-\mathrm{O}+\mathrm{BH}_{4}^{-} \rightarrow 3 \mathrm{Pt}+\mathrm{BH}_{2} \mathrm{OH}+\mathrm{OH}^{-}
$$

Como pode ser claramente visto, a produção de sítios livres de platina acontece autocataliticamente: a produção de Pt catalisa sua própria produção. Essa etapa auto-catalítica pode ser responsável, por exemplo, pela segunda transição abrupta de potencial em potenciais menos positivos, (região ii na Figura 8). Outro candidato para uma etapa auto-catalítica é a produção rápida de $\mathrm{BO}_{2}^{-}$em potenciais mais altos (>1,10 V vs RHE), [13]:

$$
\mathrm{Pt}-\mathrm{BH}_{2} \mathrm{OH}+5 \mathrm{OH}^{-} \rightarrow \mathrm{BO}_{2}^{-}+4 \mathrm{H}_{2} \mathrm{O}+4 e^{-}
$$

que quando acoplada com uma etapa de adsorção e com a etapa (r12), poderia gerar um tipo similar de etapa auto-catalítica como em (r13). O conjunto de reações aqui propostas deve ser visto mais como uma tentativa do que como uma explicação definitiva. Se, por um lado, as duas etapas auto-catalíticas podem ser a princípio racionalizadas em termos da produção de sítios de platina livre, por outro lado, o platô em valores intermediários a esses propõe uma importante questão mecanística. Além de algum PtO residual, esse platô pode também refletir a presença de um intermediário adsorvido. A complexidade associada à presença de numerosos intermediários formados durante a eletro-oxidação do boroidreto não permite uma explicação detalhada de todo o transiente.

Durante a queda rápida de potencial sob condições de potencial aberto, a produção auto-catalítica de sítios de platina livre também está associada com a onda de reativação observada durante a varredura reversa em uma voltametria [5; 34], como mostrado pela Figura 7. Desta forma, essa queda abrupta no potencial caracterizada pela formação autocatalítica de sítios de platina é associada a uma condição de biestabilidade, na qual existem dois estados coexistindo em uma mesma região de parâmetros. Para o caso apresentado, os dois estados que se encontram coexistindo são a platina com óxido adsorvido e a platina livre. A região de parâmetros é a mesma, mas ainda sim esses dois estados da superfície estão presentes. Caracteriza-se então a biestabilidade do sistema. 
O efeito das condições de transporte de massa nos transientes de potencial de circuito aberto também foi avaliado. Para este caso, a polarização do eletrodo foi feita a 1,5 V vs RHE por $150 \mathrm{~s}$, com o eletrodo sendo rotacionado em diferentes velocidades de rotação. Os resultados encontram-se sumarizados na Figura 10.

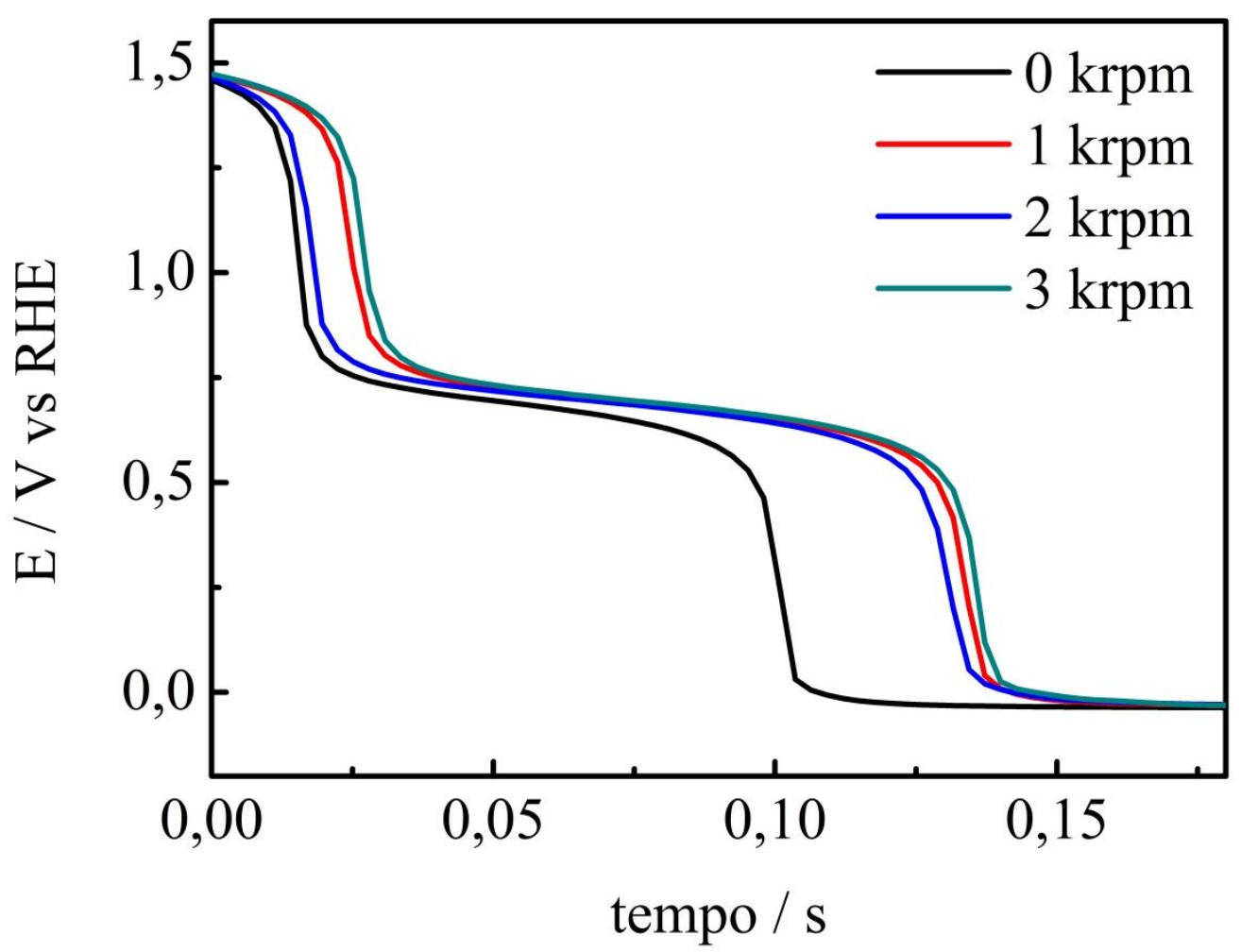

Figura 10 - Interação em potencial de circuito aberto entre o íon boroidreto e a superfície de platina oxidada em diferentes velocidades de rotação.

Pode-se observar nesta figura que o perfil das curvas se manteve o mesmo em relação às curvas feitas com o eletrodo parado. Adicionalmente é possível notar que não existe uma tendência ou uma relação clara entre a influência da velocidade de rotação do eletrodo e o tempo em que o íon leva para reduzir o óxido de platina. Desta forma, conclui-se que o transporte de massa não é um fator essencial nesse processo e que a rotação do eletrodo praticamente não afeta a interação em circuito aberto.

Concluídos os estudos sobre a biestabilidade do sistema, foram avaliadas as oscilações de corrente obtidas em experimentos quasi-estacionários utilizando diferentes valores de resistência externa e as oscilações de baixa frequência obtidas na ausência de resistência externa presentes em uma ampla faixa de potencial. Considerando o baixo tempo apresentado que o sistema leva para reduzir o óxido de platina, espera-se que o ciclo de retro-alimentação negativo exibido na Figura 2 seja rápido. A alternância entre o ciclo positivo e os ciclos 
negativos, como já discutido na Seção 1, pode levar ao processo oscilatório desde que a escala de tempo em que o inibidor ocorrer for mais lenta que a do ativador [15].

\section{3 - Oscilações na PresenÇa de ResistênCia Externa}

Com os resultados apresentados na seção anterior, intui-se que a interação em circuito aberto entre o íon boroidreto e a superfície de platina oxidada não ocorra de forma simples. Existem algumas características complexas nesse processo das quais podemos apontar, segundo Whitesides [42]: um sistema complexo é aquele cuja evolução é muito sensível às condições iniciais ou à pequenas perturbações; aquele no qual o número de componentes independentes interagindo é alto; ou ainda aquele que tem vários caminhos reacionais pelo qual pode evoluir. Desta forma, se observarmos o número de intermediários presentes no processo de eletro-oxidação, hidrólise heterogênea, e ainda que em menor proporção, hidrólise homogênea, pode-se concluir que existem muitos componentes independentes interagindo e que certamente o sistema pode evoluir por vários caminhos reacionais. Diante dessas observações e considerando que o sistema apresentado anteriormente encontrava-se em uma condição afastada do equilíbrio termodinâmico e rapidamente traçava seu caminho rumo a este, uma investigação mais detalhada sobre o comportamento na região de altos sobrepotenciais faz-se necessária.

Os estudos sobre a emergência de propriedades como as oscilações envolvem o uso de algumas estratégias. Primeiramente, faz-se uma varredura de corrente de forma lenta, a fim de se avaliar se em algum momento as oscilações se manifestam. Em seguida, utilizam-se resistências externas ligadas em serie ao eletrodo de trabalho e faz-se varreduras de potencial. Posteriormente, fazem-se experimentos sob controle potenciostático com as resistências externas a fim de se avaliar sob quais parâmetros o sistema apresenta as oscilações. Finalmente, quando todos os parâmetros nos quais as oscilações se manifestam estão determinados, desenham-se mapas de oscilação e podem-se realizar as análises posteriores como, por exemplo, avaliar qual é o tipo do sistema de trabalho, e.g. N-NDR.

Os experimentos de varredura de corrente não se encontram aqui apresentados, pois não apresentaram oscilações tampouco alguma outra característica interessante. A Figura 11 apresenta o resultado de uma varredura de potencial, de 1,65 a $0,15 \mathrm{~V}$ vs RHE a $10 \mathrm{mV} . \mathrm{s}^{-1}$ utilizando-se uma placa de platina policristalina como eletrodo de trabalho. 


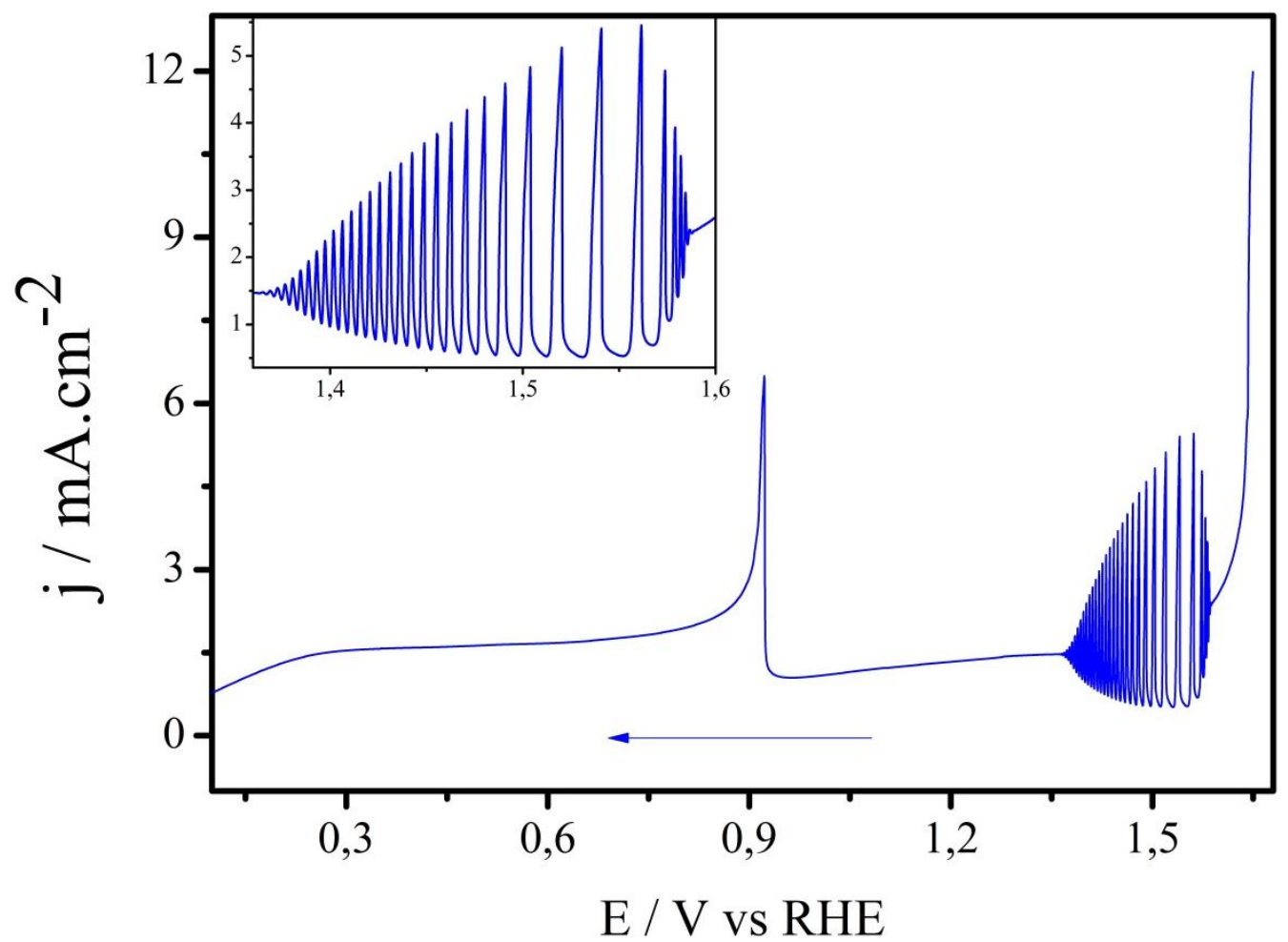

Figura 11 - Oscilações de corrente durante a eletro-oxidação de boroidreto $5 \mathrm{mM}$ em platina. Eletrólito: $\mathrm{NaOH} 1 \mathrm{M}$, Resistência Externa: $500 \Omega$, Velocidade de varredura: $10 \mathrm{mV} \cdot \mathrm{s}^{-1}, \mathrm{~T}=25 \pm 1{ }^{0} \mathrm{C}$.

A Figura 7 apresenta uma voltametria cíclica típica para o íon boroidreto. Nesta figura é possível observar dois picos de reativação na varredura reversa da voltametria, comportamento este diferente ao de moléculas orgânicas no qual somente se apresenta um pico. Ao se acoplar uma resistência externa em serie ao eletrodo de trabalho, fornece-se ao sistema um grau de liberdade adicional: uma maior queda ôhmica. Com esse grau de liberdade, o sistema encontra parâmetros suficientes para que as oscilações emerjam, como exibido na Figura 11. As oscilações contém as seguintes características: Frequência média: 1,4 Hz; Amplitude Máxima: 4,72 mA.cm²; Número de oscilações: 33. O fato de que as oscilações somente são encontradas na varredura reversa da voltametria cíclica relaciona-se com os resultados apresentados anteriormente para a interação em potencial de circuito aberto no sentido de que ambas surgem de uma interação do íon boroidreto com um filme de óxido na superfície da platina. Neste ponto vale ressaltar que a interação entre o íon e o óxido de platina, estudada na Seção 4.2, exerce influência no ciclo de retro-alimentação negativo exibido na Figura 2.

Uma característica interessante a ser apontada por esse resultado é que as oscilações se apresentam em uma faixa de potenciais, o que permite fazer um mapeamento de parâmetros variando-se as resistências externas e observando-se a faixa de potenciais na qual as 
oscilações ocorrem. Na Figura 12 encontra-se disposto o mapeamento dessa região de parâmetros na qual as oscilações em modo potenciodinâmicos são encontradas:

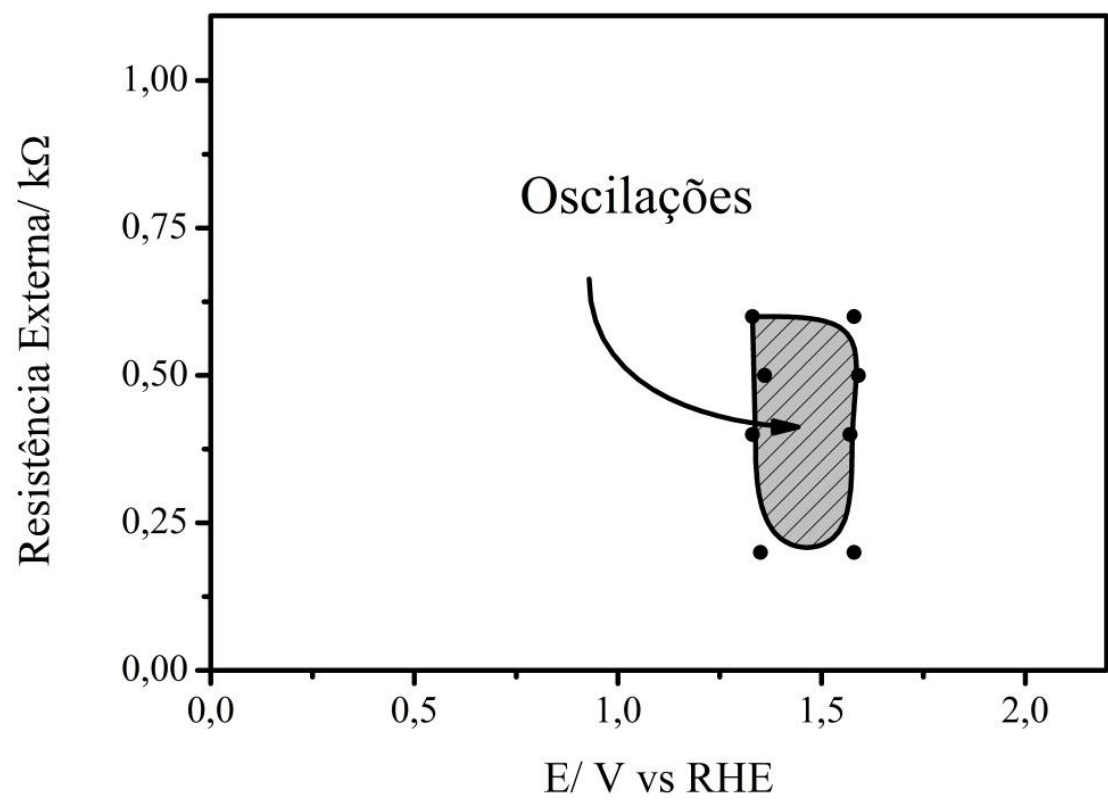

Figura 12 - Regiões de oscilação potenciodinâmica em um mapa do tipo resistência externa vs potencial aplicado.

A Figura 12 apresentada indica que existe uma região restrita de resistências externas que permitem que o sistema oscile. Sistemas que apresentam esse tipo de comportamento são classificados como do tipo N-NDR. Segundo Krischer [16] existem três principais características em um sistema do tipo N-NDR:

(i) Uma curva corrente-potencial com formato de N para resistências ôhmicas baixas;

(ii) Oscilações na região de coeficiente angular negativo para valores intermediários;

(iii) Comportamento biestável sob controle de corrente e para altos valores de resistência de eletrólito.

Como se pode observar na Figura 12, em baixas resistências não há oscilações enquanto que para resistências ôhmicas intermediárias elas se apresentam de forma estável. A resistência do eletrólito foi avaliada por meio de uma medida de espectroscopia de impedância eletroquímica e seu valor foi calculado como sendo de aproximadamente $3 \Omega$. Desta forma, como o valor da resistência do eletrólito era baixo, sob controle de corrente não foi observado o comportamento biestável. Ainda assim o comportamento apontado satisfaz as 
condições descritas pela autora [16] e portanto considera-se que o sistema estudado aqui aproxima-se em definição de um sistema do tipo N-NDR.

Além das análises realizadas, outro importante tipo de observação a ser feita refere-se ao comportamento do sistema diante de condições estacionárias, exibida na Figura 13.

(a)

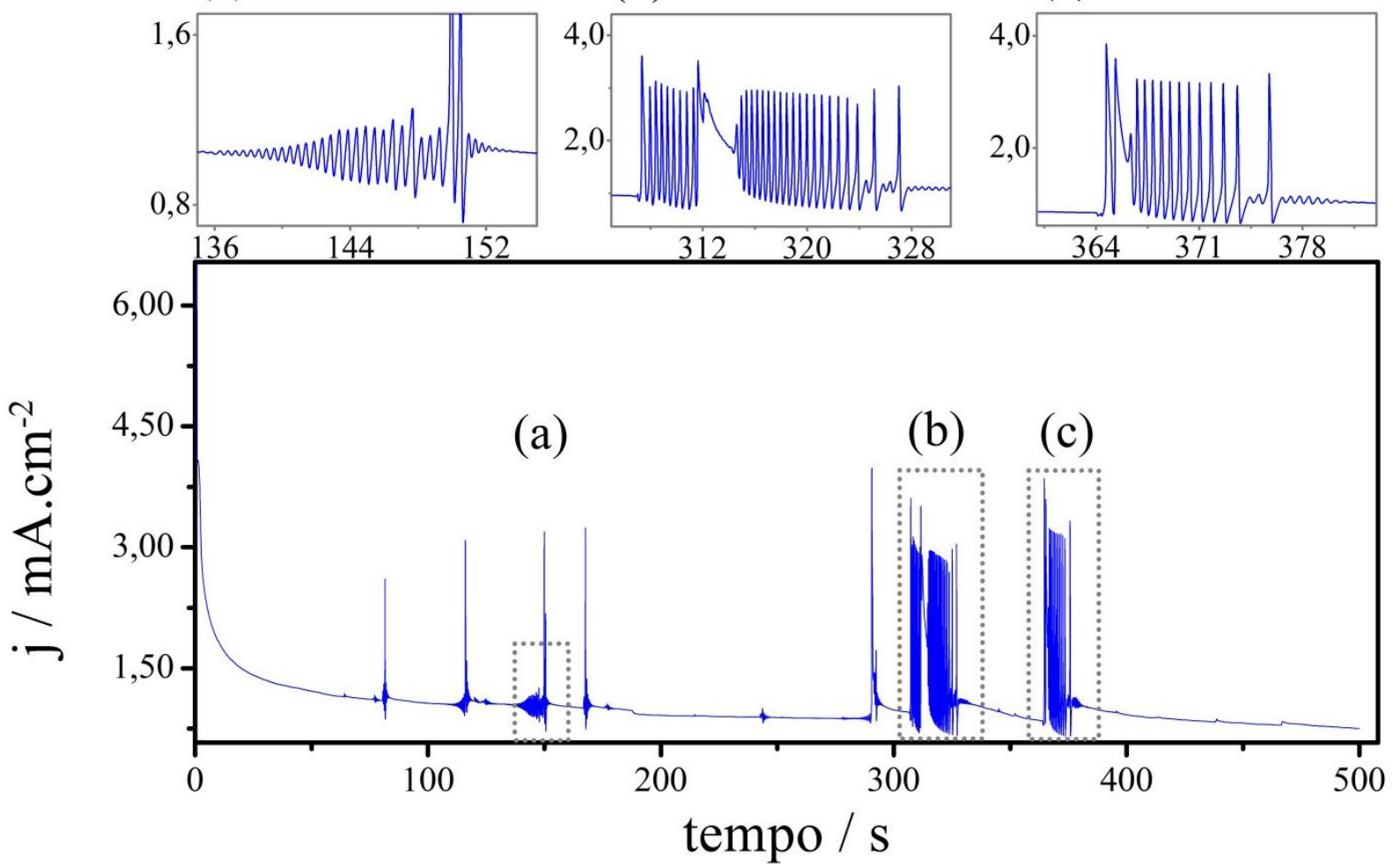

Figura 13 - Cronoamperometria em $1.4 \mathrm{~V}$ vs RHE com uma resistência externa ligada em serie ao eletrodo de trabalho de $0,5 \mathrm{k} \Omega$. O pré-tratamento utilizado foi de $1,5 \mathrm{~V}$ vs RHE por $1 \mathrm{~s}$.

É possível observar nessa figura que o perfil oscilatório não se estabiliza. Isso acontece por conta da formação de bolhas de hidrogênio na superfície do eletrodo. Desconhece-se se a causa da ocorrência dessas é a hidrólise heterogênea ou como subproduto da eletro-oxidação. Entretanto, quando o sistema começa a oscilar uma bolha de hidrogênio adsorve-se na superfície do eletrodo e é possível observar que as oscilações param. Em seguida, quando essa bolha desprende-se, volta-se o perfil oscilatório que cessa quando o processo anterior se repete. Dessa forma, não foi possível estabilizar um perfil oscilatório para que análises mais profundas de amplitude e frequência pudessem ser realizadas. Uma possível explicação para esse fenômeno pode ser a de que o hidrogênio que é gerado por um processo natural de hidrólise heterogênea do boroidreto, se adsorva na superfície do eletrodo e evite a presença de oscilações. Desta forma, dois efeitos podem estar presentes: possivelmente uma 
interação química entre o hidrogênio e algum intermediário essencial às oscilações ou uma simples mudança abrupta de área superficial, o que poderia modificar as condições de transporte de massa e assim inibir as oscilações. Experimentos futuros podem ser sugeridos como, por exemplo, a aferição do pH próximo ao eletrodo de trabalho pois espera-se que, se o hidrogênio estiver interagindo com intermediários da eletro-oxidação do boroidreto, haja uma variação local de $\mathrm{pH}$. Outro experimento a ser sugerido consiste em se alterar a área superficial do eletrodo durante uma oscilação e observar se essa alteração leva a um fim das oscilações.

Um problema a ser destacado a respeito dessas oscilações é que, devido a problemas externos provavelmente relacionados com a grande quantidade de rotas reacionais presentes no sistema, por vezes o perfil oscilatório não é reprodutível. Pequenas condições iniciais podem provocar alterações significativas na resposta e devem ser cuidadosamente controladas. Além dos problemas apontados, outro problema fora de controle é a formação de bolhas, tanto por hidrólise heterogênea quanto pela eletro-oxidação do íon boroidreto. Essas bolhas adsorvem-se na superfície do eletrodo e podem alterar as condições reacionais. Medidas a fim de evitá-las foram tomadas, como usar um eletrodo rotatório ou colocar a célula eletroquímica dentro de um banho de ultrassom. Entretanto nenhuma dessas foi efetiva uma vez que o eletrodo rotatório altera as condições difusionais e não permite que as oscilações se manifestem e o banho de ultrassom causou uma perturbação mecânica no sistema, impedindo-se a obtenção de um resultado adequado.

\section{4 - OSCILAÇõeS NA AusÊnCIA de RESISTÊNCIA EXTERNA}

Além das oscilações apresentadas com a resistência externa ligada em serie ao eletrodo de trabalho, outras oscilações puderam ser obtidas em condições diferentes. Nessas, não foi utilizada uma resistência externa e a velocidade de varredura era de $1 \mathrm{mV} . \mathrm{s}^{-1}$. Desta forma, o perfil das oscilações obtidas são diferentes e estão expostos na Figura 14. 


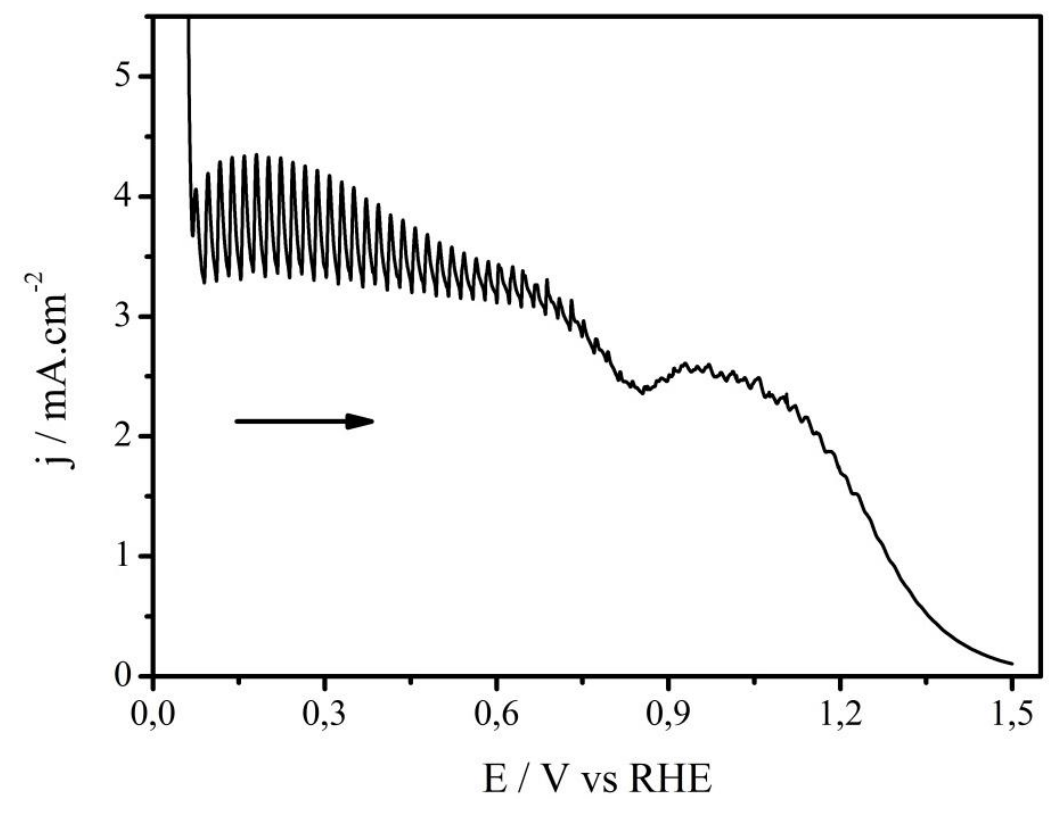

Figura 14 - Varredura no sentido de aumento de potencial, do íon boroidreto $5 \mathrm{mM}$, a $1 \mathrm{mV} . \mathrm{s}^{-1}$. Pré-tratamento de $1,5 \mathrm{~V}$ vs RHE por $15 \mathrm{~s}$.

$\mathrm{Na}$ Figura 14 pode-se observar a presença de oscilações que começam em aproximadamente 0,05 V vs RHE e vão até aproximadamente 1,2 V vs RHE. Essas oscilações são de período 1 e apresentam baixa amplitude. Como características, podemos destacar: Frequência média: 0,05 Hz; Número de oscilações: 34; Amplitude máxima: 1,13 mA.cm². De forma semelhante, na Figura 15 pode-se observar a presença de oscilações no sentido de diminuição de potencial. Estas se apresentam de 0,75 V vs RHE a aproximadamente $0,05 \mathrm{~V}$ vs RHE. 


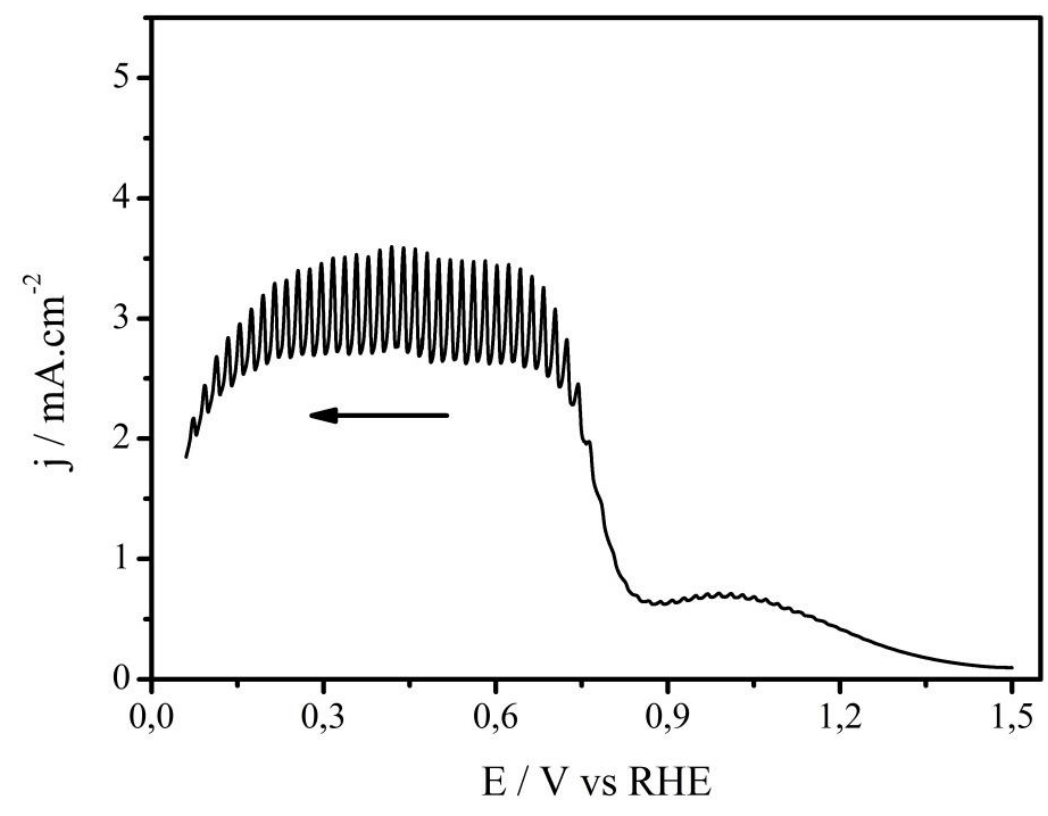

Figura 15 - Varredura no sentido de diminuição de potencial, do íon boroidreto $5 \mathrm{mM}$, a $1 \mathrm{mV} \cdot \mathrm{s}^{-1}$. Pré-tratamento de $1,5 \mathrm{~V}$ vs RHE por $15 \mathrm{~s}$.

As características das oscilações apresentadas na Figura 15 são: Frequência média: 0,05 Hz; Número de Oscilações: 35; Amplitude Máxima: 1,01 mA.cm². Os resultados encontram-se resumidos na Tabela 2 , onde $\mathrm{R}=500 \Omega$ significa as oscilações obtidas na varredura com resistência externa acoplada e o sentido positivo e negativo nos resultados sem resistência externa referem-se a varreduras no sentido de aumento e diminuição de potencial, respectivamente.

Tabela 2 - Características das oscilações obtidas em duas diferentes condições: varredura de potencial com resistência externa acoplada e varredura de potencial sem resistência externa acoplada.

$\begin{array}{cccc}\text { Número de } & \text { Frequência } & \text { Amplitude Máxima } & \text { Duração da } \\ \text { Oscilações } & \text { Média }(\mathrm{Hz}) & \left(\mathrm{mA} . \mathrm{cm}^{-2}\right) & \text { Serie (s) }\end{array}$

$\begin{array}{lllll}\mathrm{R}=500 \Omega & 33 & 1,4 & 4,72 & 23\end{array}$

Sem resistência

externa (sentido

positivo)

Sem resistência

externa (sentido

negativo). 
Uma comparação entre as oscilações obtidas com a resistência externa acoplada e essas oscilações sem resistência externa apontam que as sem resistência são de menor frequência e de menor amplitude. Entretanto elas apresentam uma duração maior, estando presentes praticamente ao longo de toda a faixa de potencial da varredura. Por terem comportamentos tão distintos, intui-se que os mecanismos por trás dos dois tipos de oscilação são diferentes. Especificamente, para o caso das oscilações com resistência externa, a frequência de oscilação é duas ordens de grandeza maior que as demais. Uma possível explicação reside no fato de que, como apontado no final da Seção 4.2, existe uma alta velocidade das reações que compõe os ciclos de retro-alimentação.

Uma hipótese foi levantada a fim de explicar as oscilações sem resistência externa: uma oscilação química que ocorreria de forma independente do potencial do eletrodo. Segundo Strasser e colaboradores [43], sistemas deste tipo representam osciladores puramente químicos envolvendo pelo menos uma etapa eletroquímica, na qual uma das reações químicas é associada com transferência de carga na interface do eletrodo. Neste caso, para valores finitos de resistência, o potencial do eletrodo $(\varphi)$ se torna dependente do tempo e pode até ser parte de um ciclo de retro-alimentação não-essencial. As oscilações químicas aconteceriam, supostamente, por conta dos intermediários formados nas hidrólises homogêneas e heterogêneas, de forma que o eletrodo seria apenas uma espécie de sonda e não um participante do processo. Esse tipo de oscilador é identificado testando-se se $\varphi$ é ou não uma variável essencial. Por definição, uma variável não-essencial pode ser mantida constante sem alterar qualitativamente as oscilações das variáveis restantes.

Em um oscilador eletroquímico, a natureza de $\varphi$ pode ser testada potenciostaticamente com $\mathrm{R}$ tendendo a 0 (limite estritamente potenciostático) que normalmente é alcançado usando uma técnica de compensação de $I R$ (produto da corrente pela resistência, queda ôhmica). Se para resistências ôhmicas quase nulas as oscilações de corrente persistirem, estão demonstradas a natureza não-essencial de $\varphi$ e a presença de um oscilador químico. No entanto o que ocorreu foi o desaparecimento do perfil oscilatório ao se aplicar a compensação de $I R$, indicando que $\varphi$ era um parâmetro essencial para a oscilação. A hipótese da oscilação química foi então descartada. O mecanismo pelo qual esse tipo de oscilação emerge ainda é desconhecido e experimentos posteriores devem ser realizados a fim de identificá-lo. Possivelmente com o auxílio de técnicas in situ como espectroscopia de infravermelho e on line com o DEMS (espectroscopia de massa eletroquímica diferencial) seria possível descobrir quais espécies estariam interagindo na interface eletrodo/solução. 
Além dos experimentos em condições dinâmicas, foram realizadas varreduras em condições potenciostáticas, fixando-se o parâmetro potencial aplicado e avaliando-se a resposta de corrente ao longo do tempo. Os resultados encontram-se dispostos na Figura 16:

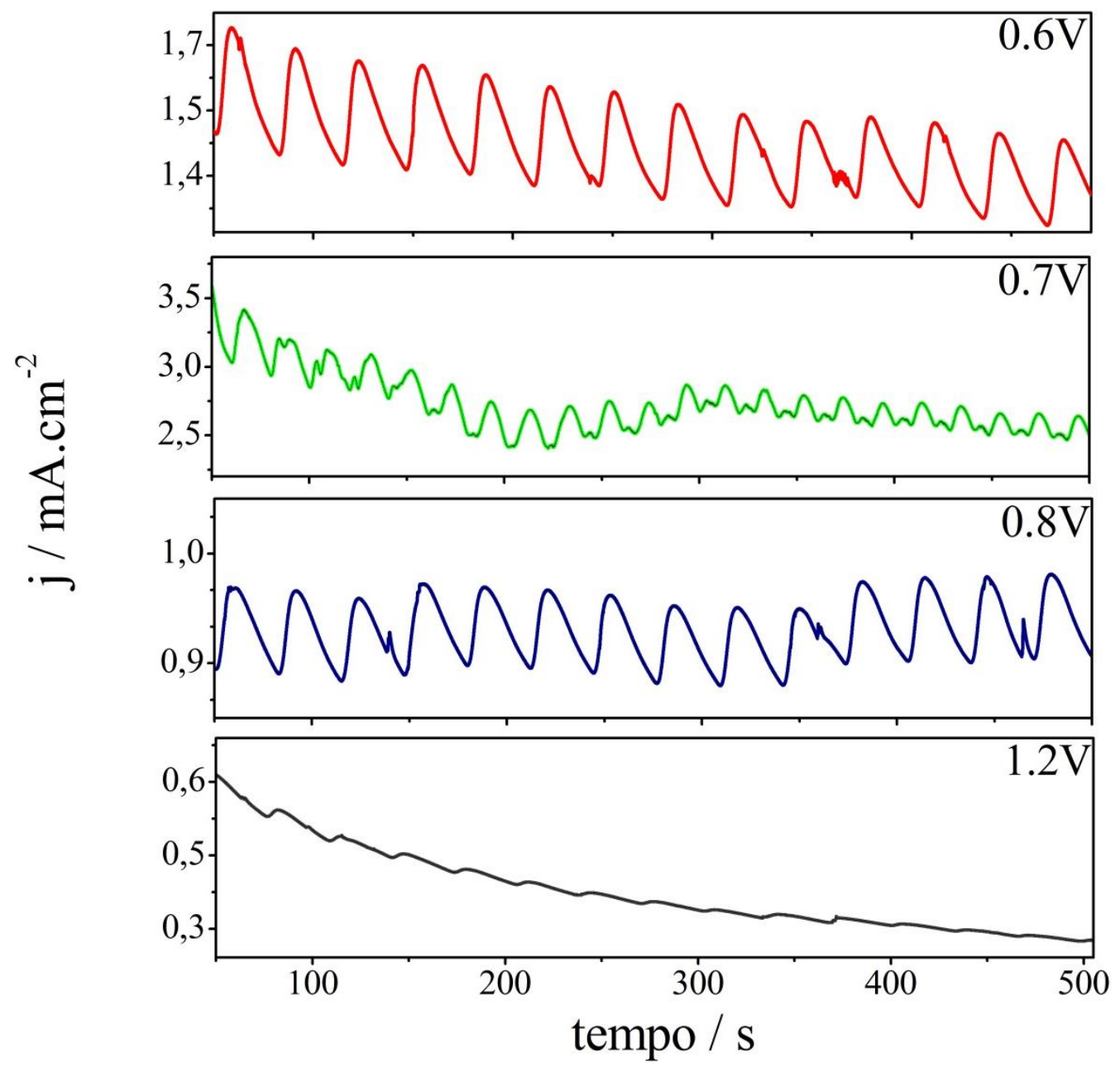

Figura 16 - Cronoamperometrias em diferentes potenciais por 500 s. Pré-tratamento de $1,5 \mathrm{~V}$ vs RHE por $15 \mathrm{~s}$ antes de cada medida.

É possível observar que as oscilações em condições estacionárias, na ausência de resistência externa acoplada, não são estáveis. Uma hipótese formulada é a de que o perfil das oscilações não se apresentou estável por conta de condições de transporte de massa não adequadas. As oscilações apresentadas na Figura 16 guardam semelhança em relação às apresentadas na varredura de potencial sem resistência. Dessa forma, intui-se que o mesmo mecanismo esteja por trás das oscilações nessas duas condições diferentes. A falta de estabilidade e reprodutibilidade inviabiliza discussões mais profundas acerca deste resultado.

Em suma, existem dois diferentes mecanismos por trás das oscilações apresentadas. Um que rege as oscilações com resistência externa acoplada e outro para o caso das oscilações 
sem resistência externa. Em ambos os casos as oscilações não se apresentaram de forma reprodutível, sendo este um indício de que o sistema é extremamente dependente das condições iniciais e do transporte de massa. Os resultados apresentados ilustram que as nãolinearidades estão presentes neste sistema e que a eletro-oxidação do íon boroidreto é capaz de, na região de parâmetros adequados, apresentar oscilações. Essas informações são inéditas e um refino experimental maior, aliado a técnicas de caracterização podem causar um avanço maior nessa pesquisa.

Diante das diversas formas de oscilação e condições pelas quais estas ocorrem, podese dizer que o sistema estudado apresenta um intrincado balanço de espécies derivadas do íon boroidreto, uma vez que essas são formadas como subproduto da hidrólise heterogênea e da eletro-oxidação. Outra condição desse sistema que embute uma dificuldade experimental adicional é o transporte de massa, que precisa ser bem controlado para que o sistema manifeste suas oscilações de forma estável. Sistemas mais simples estão melhores estabelecidos na literatura, como é o caso do metanol, por exemplo. Este não sofre hidrólises e as espécies geradas por ele são subprodutos da sua eletro-oxidação. Desta forma, as condições de trabalho com esse sistema são mais simplificadas e por isso suas oscilações fornecem maiores informações, inclusive até mesmo mecanísticas. Sendo uma novidade no grupo, o estudo eletroquímico sobre as não-linearidades de uma molécula não-orgânica apresenta novos desafios para essa área de estudo, portanto os resultados ainda são preliminares. Com o aprimoramento da metodologia, mais ferramentas poderão ser utilizadas e mais análises deverão ser feitas dessas oscilações apresentadas. 


\section{CONCLUSÕes}

Neste presente trabalho são apresentados os resultados sobre a cinética não-linear em condições afastadas do estado de equilíbrio termodinâmico, associada aos processos de adsorção, oxidação e interação do íon boroidreto em superfícies policristalinas de platina. Essa cinética foi estudada por duas distintas abordagens: a interação em potencial de circuito aberto e a eletro-oxidação deste íon.

A interação em potencial de circuito aberto apresenta resultados interessantes para a aplicação tecnológica, e.g. células a combustível direto, como o baixo tempo de transiente necessário para o íon reduzir o óxido de platina. Essa informação é relevante ao se avaliar o impacto da migração de um combustível de um compartimento ao outro no desempenho da célula a combustível direto. Além desse resultado, a interação apresenta um perfil que evidencia a presença de instabilidades cinéticas: dois processos distintos de redução estão presentes e ambos apresentam uma região de auto-catálise. Esta relaciona-se com a biestabilidade uma vez que ambas são definidas por critérios semelhantes.

A eletro-oxidação do íon, sob condições adequadas, exibiu oscilações espontâneas de corrente como manifestação das não-linearidades presentes no processo. Essas oscilações se manifestaram sob duas diferentes condições: com resistência acoplada e sem resistência acoplada. Os dois tipos de oscilações diferem entre si em características e supõe-se que o mecanismo por trás de ambas seja diferente. Apesar disso, para as oscilações com resistência externa acoplada, foi possível uma caracterização inicial do sistema, que se comporta como um sistema do tipo N-NDR. Posteriores experimentos são necessários a fim de se estabelecer condições reprodutíveis e repetíveis a partir das quais será possível uma análise mais profunda da relação amplitude e frequência de oscilação. Somente então etapas adicionais serão realizadas, como análises complementares, a fim de se obter informações mecanísticas.

Globalmente, os resultados ilustram pela primeira vez aspectos não lineares na eletrooxidação do íon boroidreto em platina e requerem experimentos adicionais e investigações numéricas dessa importante reação. 


\section{Perspectivas}

Como sequência do trabalho espera-se que mais experimentos sobre o mapeamento das regiões de oscilações sejam realizados, de forma a avaliar a influência de outros parâmetros no mapa apresentado. A variação de concentração, por exemplo, pode exercer uma diferença significativa no perfil e por esse motivo deve ser investigada. A seguir, experimentos objetivando a estabilização do perfil oscilatório obtido devem ser realizados para que outras informações mecanísticas possam ser obtidas.

Além das análises apresentadas, como continuação desse trabalho deverão ser realizadas técnicas in situ e online para investigar quais são os intermediários provavelmente envolvidos.

Finalmente, para o caso da interação em potencial de circuito aberto, uma continuação natural do trabalho seria o uso de diferentes catalisadores metálicos como, por exemplo o ouro, para a comparação dos perfis obtidos e o esclarecimento de possíveis rotas reacionais do sistema. Todas as propostas para sequência do tema apenas atestam a importância e complexidade da exploração completa deste tema que demandaria muito mais tempo do que o viável para a execução deste trabalho. 


\section{REFERÊNCIAS BIBLIOGRÁFICAS}

[1] DE LEON, C. P.; WALSH, F. C.; PLETCHER, D.; BROWNING, D. J.; LAKEMAN, J. B. Direct borohydride fuel cells. Journal of Power Sources, v. 155, n. 2, p. 172-181, 2006.

[2] FENG, R. X.; DONG, H.; WANG, Y. D.; AI, X. P.; CAO, Y. L.; YANG, H. X. A simple and high efficient direct borohydride fuel cell with $\mathrm{MnO}_{2}$-catalyzed cathode. Electrochemistry

Communications, v. 7, n. 4, p. 449-452, 2005.

[3] LI, Z. P.; LIU, B. H.; ARAI, K.; SUDA, S. Development of the direct borohydride fuel cell. Journal of Alloys and Compounds, v. 404-406, p. 648-652, 2005.

[4] MATSUOKA, K.; IRIYAMA, Y.; ABE, T.; MATSUOKA, M.; OGUMI, Z. Alkaline direct alcohol fuel cells using an anion exchange membrane. Journal of Power Sources, v. 150, p. 27-31, 2005.

[5] FINKELSTEIN, D. A.; DA MOTA, N.; COHEN, J. L.; ABRUNA, H. D. Rotating disk electrode (RDE) investigation of $\mathrm{BH}_{4}{ }^{-}$and $\mathrm{BH}_{3} \mathrm{OH}^{-}$electro-oxidation at $\mathrm{Pt}$ and $\mathrm{Au}$ : implications for $\mathrm{BH}_{4}^{-}$fuel cells. Journal of Physical Chemistry C, v. 113, n. 45, p. 19700-19712, 2009.

[6] CONCHA, B. M.; CHATENET, M. Direct oxidation of sodium borohydride on Pt, Ag and alloyed Pt-Ag electrodes in basic media. Part I: Bulk electrodes. Electrochimica Acta, v. 54, n. 26, p. 61196129, 2009.

[7] GYENGE, E. Electrooxidation of borohydride on platinum and gold electrodes: implications for direct borohydride fuel cells. Electrochimica Acta, v. 49, n. 6, p. 965-978, 2004.

[8] LIU, B. H.; LI, Z. P.; SUDA, S. Electrocatalysts for the anodic oxidation of borohydrides. Electrochimica Acta, v. 49, n. 19, p. 3097-3105, 2004.

[9] MIRKIN, M. V.; YANG, H. J.; BARD, A. J. Borohydride oxidation at a gold electrode. Journal of The Electrochemical Society, v. 139, n. 8, p. 2212-2217, 1992.

[10] MARTINS, J. I.; NUNES, M. C.; KOCH, R.; MARTINS, L.; BAZZAOUI, M. Electrochemical oxidation of borohydride on platinum electrodes: The influence of thiourea in direct fuel cells.

Electrochimica Acta, v. 52, n. 23, p. 6443-6449, 2007.

[11] TAROZAITE, R.; TAMASIUNAITE, L. T.; JASULAITIENE, V. Platinum-tin complexes as catalysts for the anodic oxidation of borohydride. Journal of Solid State Electrochemistry, v. 13, n. 5, p. 721-731, 2009.

[12] ELDER, J. P.; HICKLING, A. Anodic behaviour of borohydride ion. Transactions of the Faraday Society, v. 58, n. 477, p. 1852-1864, 1962.

[13] CONCHA, B. M.; CHATENET, M.; TICIANELLI, E. A.; LIMA, F. H. B. In Situ infrared (FTIR) study of the mechanism of the borohydride oxidation reaction on smooth Pt electrode. Journal of Physical Chemistry C, v. 115, n. 25, p. 12439-12447, 2011.

[14] VARELA, H. Da parte para o todo: auto-organização dinâmica em sistemas físico-químicos. Ciência e Cultura, v. 63, p. 23-25, 2011.

[15] KRISCHER, K.; VARELA, H. Oscillations and other dynamic instabilities. In: VIELSTICH, W.;LAMM, A. e GASTEIGER, H. A. (Ed.). Handbook of fuel cells: fundamentals, technology and applications. Chichester: John Wiley, 2002. v.2, p.679-701. 
[16] KRISCHER, K. Nonlinear dynamics in electrochemical systems. In: ALKIRE, R. C. e KOLB, D. M. (Ed.). Advances in electrochemical science and engineering: Weinheim: John Wiley, 2003. cap. 2, p.89-208.

[17] FRUMKIN, A. Adsorptionserscheinungen und elektrochemische kinetik. Zeitschrift Fur Elektrochemie, v. 59, n. 7-8, p. 807-822, 1955.

[18] LI, Z. P.; LIU, B. H.; ARAI, K.; ASABA, K.; SUDA, S. Evaluation of alkaline borohydride solutions as the fuel for fuel cell. Journal of Power Sources, v. 126, n. 1-2, p. 28-33, 2004.

[19] LIU, B. H.; SUDA, S. Influences of fuel crossover on cathode performance in a micro borohydride fuel cell. Journal of Power Sources, v. 164, n. 1, p. 100-104, 2007.

[20] POINTON, K.; LAKEMAN, B.; IRVINE, J.; BRADLEY, J.; JAIN, S. The development of a carbon-air semi fuel cell. Journal of Power Sources, v. 162, n. 2, p. 750-756, 2006.

[21] ROSTAMIKIA, G.; JANIK, M. J. First principles mechanistic study of borohydride oxidation over the Pt(111) surface. Electrochimica Acta, v. 55, n. 3, p. 1175-1183, 2010.

[22] MA, J.; CHOUDHURY, N. A.; SAHAI, Y. A comprehensive review of direct borohydride fuel cells. Renewable \& Sustainable Energy Reviews, v. 14, n. 1, p. 183-199, 2010.

[23] CHATENET, M.; MICOUD, F.; ROCHE, I.; CHAINET, E.; VONDRAK, J. Kinetics of sodium borohydride direct oxidation and oxygen reduction in sodium hydroxide electrolyte - Part II. $\mathrm{O}_{2}$ reduction. Electrochimica Acta, v. 51, n. 25, p. 5452-5458, 2006.

[24] BATISTA, B. C.; SITTA, E.; EISWIRTH, M.; VARELA, H. Autocatalysis in the open circuit interaction of alcohol molecules with oxidized Pt surfaces. Physical Chemistry Chemical Physics, v. 10, n. 44, p. 6686-6692, 2008.

[25] BREITER, M. W. Reduction mechanism of chemisorbed oxygen on platinum electrodes by molecular hydrogen. Journal of The Electrochemical Society, v. 109, n. 5, p. 425-427, 1962.

[26] BURKE, L. D.; MOYNIHAN, A. Kinetics of the chemical reduction of platinum-black surface oxides. Electrochimica Acta, v. 15, n. 9, p. 1437-1443, 1970.

[27] MANZHOS, R. A.; PODLOVCHENKO, B. I.; MAKSIMOV, Y. M. Specific features of interaction between formic acid and oxygen adsorbed on smooth polycrystalline platinum: Transients of the open-circuit potential. Russian Journal of Electrochemistry, v. 42, n. 6, p. 658-664, Jun 2006.

[28] MANZHOS, R. A.; PODLOVCHENKO, B. I.; MAKSIMOV, Y. M. Special features of methanol interaction with adsorbed oxygen at platinized platinum electrode: Transients of the open-circuit potential. Russian Journal of Electrochemistry, v. 43, n. 11, p. 1268-1272, 2007.

[29] OXLEY, J. E.; JOHNSON, G. K.; BUZALSKI, B. T. The anodic oxidation of methanol: Opencircuit transient reactions. Electrochimica Acta, v. 9, n. 7, p. 897-910, 1964.

[30] PODLOVCHENKO, B. I.; MANZHOS, R. A.; MAKSIMOV, Y. M. Transients of the opencircuit potential during carbon monoxide interaction with oxygen preliminarily adsorbed on smooth and platinized platinum electrodes. Russian Journal of Electrochemistry, v. 38, n. 12, p. 1292-1298, 2002.

[31] SITTA, E.; VARELA, H. On the open-circuit interaction between methanol and oxidized platinum electrodes. Journal of Solid State Electrochemistry, v. 12, n. 5, p. 559-567, 2008. 
[32] SMOLIN, A. V.; PODLOVCHENKO, B. I.; MAKSIMOV, Y. M. Formaldehyde interaction with adsorbed oxygen on open-circuit platinum electrodes in aqueous sulfuric acid solutions. Russian Journal of Electrochemistry, v. 45, n. 3, p. 246-251, 2009.

[33] VARELA, H.; SITTA, E.; BATISTA, B. C. Methanol oxidation on oxidized Pt surface. In: VIELSTICH, W.; GASTEIGER, H. A.; LAMM, A. (Ed.). Handbook of fuel cells: fundamentals, technology and applications. Chichester: John Wiley, 2009. v.5. p.1-15.

[34] BATISTA, B. C.; VARELA, H. Open Circuit Interaction of Formic Acid with Oxidized Pt Surfaces: Experiments, Modeling, and Simulations. Journal of Physical Chemistry C, v. 114, n. 43, p. 18494-18500, 2010.

[35] PODLOVCHENKO, B. I.; MANZHOS, R. A.; MAKSIMOV, Y. M. Kinetics and mechanism of interaction between methanol and adsorbed oxygen on a smooth polycrystalline platinum electrode: Transients of the open-circuit potential. Russian Journal of Electrochemistry, v. 42, n. 10, p. 10611066, 2006.

[36] TRASATTI, S.; PETRII, O. A. Real surface-area measurements in electrochemistry. Pure and Applied Chemistry, v. 63, n. 5, p. 711-734, 1991.

[37] HAMANN, C. H.; HAMNETT, A.; VIELSTICH, W. Electrochemistry. $2^{\text {nd }}$ ed. Weinheim: Wiley-VCH, 2007.

[38] BELLAVANCE, M. I.; MILLER, B. The electrochemistry of boron. In: BARD, A. J. (Ed.). Encyclopedia of electrochemistry of the elements. New York: Marcel Dekker, 1974. v.2.

[39] VARELA, H.; KRISCHER, K. Nonlinear phenomena during electrochemical oxidation of hydrogen on platinum electrodes. Catalysis Today, v. 70, n. 4, p. 411-425, 2001.

[40] GERVASIO, D.; XU, M.; THOMAS, E. Properties of aqueos alkaline sodium borohydride solutions and by-products formed during hydrolisis. Fuel Cell Design, Fabrication and Materials Selection Workshop. Illinois, 2005.

[41] RICHARDSON, B. S.; BIRDWELL, J. F.; PIN, F. G.; JANSEN, J. F.; LIND, R. F. Sodium borohydride based hybrid power system. Journal of Power Sources, v. 145, n. 1, p. 21-29, 2005.

[42] WHITESIDES, G. M.; ISMAGILOV, R. F. Complexity in chemistry. Science, v. 284, p. 89-92, 1999.

[43] STRASSER, P.; EISWIRTH, M.; KOPER, M. T. M. Mechanistic classification of electrochemical oscillators - operational experimental strategy. Journal of Electroanalytical Chemistry, v. 478, n. 1-2, p. 50-66, 1999. 